DIFFERENT STROKES FOR DIFFERENT TEAMS: THE CONTINGENT EFFECTS

OF POSITIVE AND NEGATIVE FEEDBACK ON THE CREATIVITY OF

INFORMATIONALLY HOMOGENEOUS AND DIVERSE TEAMS

\author{
INGA J. HOEVER \\ Erasmus University Rotterdam \\ Burgemeester Oudlaan 50 \\ 3062 PA Rotterdam, The Netherlands \\ e-mail: ihoever@rsm.nl \\ JING ZHOU \\ Rice University \\ 6100 Main Street \\ Houston, TX 77005 \\ e-mail: jzhou@ rice.edu
}
DAAN VAN KNIPPENBERG
Drexel University
3220 Market Street
Philadelphia, PA 19104
e-mail: dlv39@drexel.edu

Acknowledgement. We gratefully acknowledge the help of Timo van Balen and Hubertus Riedesel Freiherr zu Eisenbach in coding the data as well as of Nathan E. Betancourt for careful readings and comments on the paper. Furthermore, we would like to thank the Vereniging Trustfonds Erasmus Universiteit Rotterdam and the Jones Graduate School of Business at Rice University for their financial support for this international research collaboration. 


\title{
DIFFERENT STROKES FOR DIFFERENT TEAMS: THE CONTINGENT EFFECTS OF POSITIVE AND NEGATIVE FEEDBACK ON THE CREATIVITY OF INFORMATIONALLY HOMOGENEOUS AND DIVERSE TEAMS
}

\begin{abstract}
Feedback is a ubiquitous management tool. Employing this tool to meet the new challenge of enhancing team creativity, raises the important question of whether positive or negative feedback is more effective. Unfortunately prior research on feedback valence and creativity is limited to the individual level, neglecting team creativity's interdependent and knowledge-intensive nature. We address this issue and advance the team information processing perspective on team creativity by integrating two heretofore separate research streams to develop a team-specific model about how negative and positive feedback enhance creativity via two alternative information processing routes, contingent on teams' informational diversity. Negative feedback fuels teams' systematic effort and attention to external, novel information. In informationally diverse teams, in which members hold different information and perspectives, these efforts promote team creativity through information elaboration. Conversely, positive feedback propels members to flexibly use their information and contribute the resultant divergent insights to the team. In informationally homogeneous teams, where these insights relate to others' information and perspectives, these divergent insights trigger teams' generative processing and in turn creativity. Results from a team experiment support the predicted feedback valence by informational diversity interaction on team creativity through elaboration and generative processing.
\end{abstract}

Keywords: Creativity; Group/team processes; Lab experiment 
Creativity is highly prized in organizations (Florida \& Goodnight, 2005) and managers express a keen interest in tools that allow them to boost workplace creativity (Barsh, Capozzi, \& Davidson, 2008). One promising tool in this regard is feedback which represents one of the most common ways to motivate and direct employee behavior (Herold \& Greller, 1977; Kluger \& DeNisi, 1996; Nadler, 1979). For creative tasks, feedback is defined as information provided by others regarding the extent to which ideas are creative compared to a relative or absolute standard (Zhou, 1998). Reflecting the desirability of creativity and the ubiquity of feedback in organizations, prior research has studied the impact of feedback - and in particular of feedback valence as one of feedback's most fundamental dimensions - on individuals' creativity (see Zhou, 2008 for a review). The core finding from this line of work is that positive feedback yields higher creativity than negative feedback (Fodor, 1990; Zhou, 1998; cf. Fodor \& Greenier, 1995) because of its favorable affective and motivational consequences.

This research offers valuable insights on how to promote individuals' creativity through feedback. Nonetheless, it fails to take an increasing reality of modern organizations into account: Work, and especially creative work (Wuchty, Jones, \& Uzzi, 2007), is often carried out in teams (Ilgen, Hollenbeck, Johnson, \& Jundt, 2005). This raises the important question of how positive and negative feedback affect team creativity. Both individual and team creativity focus on the joint novelty and usefulness of ideas and solutions (Amabile, 1996; George, 2007). Yet the distinguishing feature of team creativity is that these solutions are developed by multiple interdependent actors (cf. Gilson \& Shalley, 2004; Hoever, van Knippenberg, van Ginkel, \& Barkema, 2012). Indeed, prior work has argued that the core promise of using teams for creative tasks lies in teams harnessing their members' informational resources through their interdependent actions to achieve creative synergy (e.g., Harvey, 2014; Kurtzberg \& Amabile, 
2001; Taggar, 2001). Accordingly, understanding the effects of feedback valence on team creativity requires examining its impact on teams' interdependent information processing. As these processes lack direct individual-level equivalents, the answer to the question of how feedback valence affects team creativity is unlikely to be found in a mere extension of individual-level accounts. Instead, it requires a unique team-level perspective.

To develop team-specific theory on how feedback valence affects creativity, we draw on the teams as information processors lens (Hinsz, Tindale, \& Vollrath, 1997) that lies at the core of our understanding of team creativity (van Knippenberg, 2017). The conclusion of our analysis is that to understand the effects of feedback valence on team creativity, we need to integrate the two heretofore largely separate research streams within the information processing perspective on team creativity. This integration not only serves our research purpose, but also has implications for team creativity research at large. Whereas the team creativity literature rooted in work on team performance and decision making suggests that feedback promotes team creativity when it fosters information elaboration (van Knippenberg, 2017), a separate research stream rooted in the brainstroming tradition stresses the importance of members cognitively stimulating each other's novel insights (Paulus \& Nijstad, 2003). The teams as information processors lens (Hinsz et al., 1997) offers a conceptual approach to team information processing mechanisms that we use to compare these processes and their role in feedback's effect on creativity. Specifically this lens views team information processing as comprising members' individual contributions and teams' combinatorial processes. Both elements are shaped by team characteristics, especially a team's informational diversity - or the extent to which members hold different information and viewpoints (Homan, van Knippenberg, Van Kleef, \& De Dreu, 2007). Informational diversity represents a core dimension on which teams differ and that affects the 
nature of members' contributions and teams' combinatorial processes (Hinsz et al., 1997). Pairing this lens with the insight that creativity can either stem from a recombination of existing material or the introduction of new material (Oldham \& Cummings, 1996), we theorize that feedback valence exerts its effect through two alternative information processing routes that feature different combinations of contributions and build on different informational foundations.

Reflecting the logic of fostering creativity by recombining existing materials, creativity is driven by teams' ability to integrate members' contributions in the form of different information and views (van Knippenberg, 2017). Team information elaboration, or the sharing, discussion, and integration of members' informational resources (van Knippenberg, De Dreu, \& Homan, 2004), is a prime example of an integrative process that fosters team creativity (Hoever et al., 2012). It builds on members bringing different views and knowledge to the task (i.e., on informational diversity) but also stresses the need to combine these through integration such that the output contains elements of multiple members' contributing input. Team creativity can also be enhanced through team generative processing which entails that members stimulate each other to generate new and useful insights (Dugosh, Paulus, Roland, \& Yang, 2000; Torrance, 1971). This requires members to use their information flexibly and share the divergent insights gained from this with the team where they serve as triggers for others' insights. Whereas the team process nature of generative processing is evidenced in that the contribution of one member triggers another's contribution, this new contribution need not incorporate the input that triggered it. As such, an integration of contributions may occur but is not defining of generative processing (as it is for elaboration). A member's contributions are more likely to trigger another member's insight when they relate to that member's knowledge (Dugosh \& Paulus, 2005; Harvey, 2013). Hence, generative processing is facilitated by informational homogeneity, which 
affords teams with a shared knowledge base (Bunderson \& Sutcliffe, 2002).

A key insight that we gain from applying the teams as information processors lens to elaboration and generative processing is that informationally diverse and homogeneous teams are differentially suited to engage in each of these processes. This matters for understanding how feedback valence affects team creativity because the effects associated with positive and negative feedback play to the respective strengths of informationally homogeneous and diverse teams. In contrast to the main effect of feedback valence on individual creativity, this means that for teams each type of feedback can promote creativity through one of the two alternative information processing routes so long as the feedback's valence fits with the team's informational diversity. Specifically, the effects of negative feedback complement the availability of different information and views in informationally diverse teams to elicit elaboration. Negative feedback promotes teams' effort and strategizing (Mesch, Farh, \& Podsakoff, 1994; Weldon \& Weingart, 1993), and individuals' re-evaluation of task and resources (Wofford \& Goodwin, 1990). Hence it may prompt teams to carefully search for and combine their unshared informational resources. When members possess a lot of unshared information and views, negative feedback may foster elaboration and in turn team creativity. Conversely, positive feedback combines with the stronger shared knowledge base of informationally homogeneous teams to elicit generative processing. Positive feedback, via its effects on positive affect, makes individual members use their existing information more flexibly (cf. Bless \& Fiedler, 2006; Estrada, Isen, \& Young, 1994). When team members hold mostly shared information and views, these contributions are more likely to trigger teammates' insights than in teams lacking shared knowledge (Dugosh \& Paulus, 2005; cf. Harvey, 2013). The resultant higher levels of generative processing benefit teams' creativity.

In sum, raising the crucial question of how the commonly used managerial tools of 
positive and negative feedback affect the highly interdependent and knowledge-intensive outcome of team creativity leads us to build a theoretical model that sets team information processing center stage. With this model, we advance the team information processing literature on team creativity by integrating two important but previously largely disconnected research streams and change the conversation about how feedback valence relates to team creativity.

The team information processing perspective is arguably the key theoretical lens on team creativity and reflects companies' core rationale for using teams for creative tasks (Anderson, Potočnik, \& Zhou, 2014; cf. Hülsheger, Anderson, \& Salgado, 2009; van Knippenberg, 2017). Despite this consensus about the relevance of team information processing, two different streams of this literature have focused on different mechanisms. Each stream provides evidence for the effectiveness of its focal mechanism, yet research to date lacks a systematic comparison of these mechanisms and their antecedents. Our analysis of elaboration and generative processing through the teams as information processors lens exposes their differences in terms of contributions, combinatorial processes, and informational foundations thereby offering a way to move beyond the implicit assumption that they are separate but equally important routes to team creativity. Indeed, by identifying informational diversity as a contingency factor of feedback valence's effect, we integrate these two views on how information processing benefits team creativity by casting elaboration and generative processing as two alternative routes to creativity that arise from distinct combinations of antecedents. This integration also adds to the teams as information processors model (Hinsz et al., 1997) which has so far considered informational diversity and external interventions like feedback as separate influences on team information processing.

Importantly, this also paves the way for two key implications for the specific question of how feedback valence affects team creativity. First, our model stresses the core role of team 
information processing not just as a precursor to team creativity but also as a mechanism in

feedback valence's effect on it. This departs from prior individual-level work which would have pointed to affective and motivational mediators of feedback's creative benefits (Zhou, 2008).

Second, applying this uniquely team-focused theoretical lens to the study of how feedback valence relates to creativity leads us to identify informational diversity - a factor with no individual-level counterpart - as a moderator of feedback valence's effect. This is in marked contrast to prior individual-level research which would have led us to predict a positive main effect of positive feedback (Zhou, 2008) and a core insight that is gained from anchoring our theorizing in a conceptual analysis of team creativity and the mechanisms most conducive to it.

\section{THEORETICAL BACKGROUND AND HYPOTHESES}

\section{The Contingent Effects of Feedback Valence on Team Creativity}

In line with contemporary research on workplace creativity, we adopt a product definition of team creativity as the joint novelty and usefulness of a final product (Amabile, 1996; Zhou \& Shalley, 2011) developed by multiple interdependent actors. We focus on the creativity of the final product for two reasons. First, different processes may lead to the same creative outcome (Anderson et al., 2014) and whether a process is relevant for creativity is usually assessed by how creative its outcome is (e.g., Amabile, 1996). Second, the creativity of the final solution is the key concern for organizations. This makes knowledge about how the common managerial tool of feedback affects the creativity of the final solution especially vital for them.

For creative tasks, feedback is defined as information provided by others regarding the extent to which ideas or solutions developed by individuals or teams are creative compared to a relative or absolute standard (Zhou, 1998; cf. Herold \& Greller, 1977; Kluger \& DeNisi, 1996; Nadler, 1979). Feedback is inherently valenced as it entails the comparison to a reference point, 
relates recipients' performance to a goal, and is expressed through others' reactions (Brendl \& Higgins, 1996). Given this fundamental role of feedback valence, or the positivity or negativity of the discrepancy between an actor's creativity and the applied standards (Zhou, 1998), prior individual-level work has explored its effect on creativity. A core finding of this work (see Zhou, 2008 for an overview) is that individuals' creativity is higher following the receipt of positive than negative feedback (Fodor 1990; Zhou, 1998; cf. Fodor \& Greenier, 1995). This effect is typically ascribed to the favorable affective and motivational consequences of positive feedback.

Notwithstanding the importance of these insights, it is crucial to realize that they were derived from individual-level research. Given the unique defining features of team creativity compared to individual creativity, these findings are unlikely to fully apply to the setting of teams receiving feedback. First, such an extrapolation neglects the interdependent nature of team creativity and with it the importance of studying feedback's effects on the processes teams use to manage this interdependence. Second, the raison d'être for creative teamwork lies in teams harnessing their larger cognitive potential further stressing the role of team information processing. Finally, the only prior study speaking to this effect found no effect of success (vs. failure) feedback on team creativity despite its positive effect on task enjoyment (Ziller, Behringer, \& Goodchilds, 1962). This underscores that the team-level effects of feedback valence on creativity are likely not reducible to their individual-level counterparts.

These considerations point to the need to adopt a theoretical lens that recognizes the interdependent and knowledge-intensive nature of team creativity. Hence, we shift to a teams as information processors lens (Hinsz et al., 1997) to study of feedback's effects on team creativity. This lens holds great promise because it focuses on the qualitatively different processes and contingencies that may affect teams' ability to achieve creative synergy following positive and 
negative feedback. Building on the insight that "the processing of information in groups involves activities that occur within as well as among the minds of group members" (p. 43), Hinsz et al. (1997) model team information processing as 'combinations of contributions'. Team information processing thus is an amalgam of two parts: Members' contributions such as knowledge and viewpoints and team combinatorial processes that link them to create an emergent team process. In line with the model's informational focus, Hinsz et al. (1997) further posit that the nature of a team's information processing is closely tied to its informational diversity. Teams' informational diversity varies along a continuum (but is rarely absolutely homogeneous or diverse) and changes with a team's information processing. Yet the relative uniqueness vs. sharedness of members' information and viewpoints is argued to shape the nature of members' contributions and the combinatorial processes teams can engage in (Hinsz et al., 1997). The pattern of combinations of contributions shaped by informational diversity also offers a lens to compare the two alternative information processing routes that different streams of the team information processing literature deem to be key to fostering team creativity.

\section{Two Alternative Team Information Processing Routes to Team Creativity}

The first route is rooted in the team performance and decision making literature and highlights that team information processing can benefit team creativity when it entails that members integrate their different information and views into a team solution (van Knippenberg, 2017). Building on the notion of recombination (Oldham \& Cummings, 1996), increased novelty and usefulness does not arise from individual contributions but from their novel linkage which may also lead to ideas that are considered useful from a broader set of perspectives. Viewed through the teams as information processors lens, teams' integrative processing builds on members' ability to contribute different information and viewpoints to the discussion and is thus 
enabled by a team's informational diversity as its informational basis. These inputs are combined through a team's integrative effort which per definition entails that the resultant output of this process contains elements of different members' contributing input.

The process of information elaboration epitomizes these characteristics. It captures the extent to which members contribute their unshared task-relevant information and viewpoints, while underscoring the importance of teams linking these contributions by integrating them into a joint solution (van Knippenberg et al., 2004). The core rationale is that sharing and discussing members' information yields more novel and useful solutions to the extent that it ensures that these solutions are integrations of different members' inputs (van Knippenberg et al., 2004). Recent research argues that this integration of members' input lies at the core of teams' ability to develop creative solutions (Hoever et al., 2012; van Knippenberg, 2017; cf. Harvey, 2014). We thus focus on the established concept of elaboration to capture a team's integrative processing.

The second information processing route to team creativity focuses on how teams benefit from members prompting each other to generate a variety of new insights. This promotes creativity by increasing the chance of generating new material through variation with potentially useful applications (cf. Campbell, 1960). The defining feature of these processes is that members stimulate each other to generate novel insights. Hence, we refer to these processes as team generative processing. This process draws from brainstorming research (Paulus \& Nijstad, 2003) which stresses the importance of developing various ideas through individual's flexible (Brown, Tumeo, Larey, \& Paulus, 1998) or divergent thinking (Guilford, 1967). This work views idea generation as a "mental process that occurs within the individual members' mind" (Nijstad, Diehl, \& Stroebe, 2003: 144). Such an individual focus makes sense within the brainstorming instructions which purposely limit certain types of team discussions. Yet when focusing on team 
creativity, one also needs to consider how the contributions resulting from individuals' flexible and divergent thinking jointly form a team process through which teams develop new insights.

Cast through the lens of teams as information processors, generative processing entails members using their own information flexibly and raising the resultant divergent inputs in the discussion. Yet these inputs only form a team process when other members pick up on and use them as a springboard for their own insights thereby linking different members' inputs. As such, generative processing features a different combinatorial process than elaboration which requires integration. In contrast, generative processing links members' contributions by having the input of one member form a trigger for, but not necessarily a part of, the resultant insight. Because members' ability to get stimulated by another's input depends on the extent to which this input activates the receiving member's own knowledge, generative processing is also facilitated by a different informational foundation. Whereas elaboration builds on informational diversity, a team's capacity for generative processing builds on a shared knowledge base (cf. Dugosh \& Paulus, 2005; Harvey, 2013) that is present to a higher degree in informationally homogeneous teams (Bunderson \& Sutcliffe, 2002). Moreover, because teams with a shared knowledge base are more likely to consider these emergent insights valid (Stasser \& Birchmeier, 2003), members of informationally homogeneous teams are also more likely to mutually enhance (Wittenbaum, Hubbell, \& Zuckerman, 1999) and reinforce each other in this generative processing.

In sum, applying the teams as information processors lens to the question of how feedback promotes team creativity suggests that the two information processing routes to team creativity (elaboration vs. generative processing) that derive from different research streams systematically differ in their combinations of member contributions (integration vs. trigger), and build on different informational foundations in teams (different task-relevant information vs. a 
shared knowledge base). This insight is important because the effects triggered by negative and positive feedback found in prior work complement the different informational foundations present in informationally diverse and homogeneous teams. In other words, combining the effects of feedback valence with the notion of informational diversity leads us to predict that positive and negative feedback may each benefit team creativity through one of the two information processing routes provided they fit with the team's informational diversity.

\section{Different strokes for different teams? The fit between feedback and informational diversity}

Negative feedback's benefits for informationally diverse teams. We posit that negative feedback has the potential to promote elaboration and creativity in informationally diverse but not homogeneous teams. Negative (compared to positive) feedback has been found to elicit more strategizing, effort, and ambitious goals in teams (Mesch et al., 1994; Weldon \& Weingart, 1993), and people receiving negative (vs. positive) feedback evaluated their task and resources more carefully, and tailored their strategies more to the given situation (Wofford \& Goodwin, 1990). Hence, teams receiving negative feedback may more deliberately search for and review the team's unused informational resources which are present to a larger degree in informationally diverse teams, and more carefully reflect on their task, strategy, and resources. This was found to promote elaboration (van Ginkel, Tindale, \& van Knippenberg, 2009). Complementing these findings, task-related negative mood has been shown to reduce individuals' reliance on their preexisting knowledge structures and heighten their attentiveness to and systematic analysis of external and novel information (Bless \& Fiedler, 2006; Bless \& Schwarz, 1999; Bohner, Bless, Schwarz, \& Strack, 1988). The increased focus on new, external information following negative feedback makes unshared information especially suitable to overcome the shortcomings signaled by this feedback. Indeed, negative affect was found to boost elaboration in teams with distributed 
(but not shared) information (Kooij-de Bode, van Knippenberg, \& van Ginkel, 2010).

In informationally homogeneous teams, the described effects of negative feedback are unlikely to promote elaboration. Teams with largely shared information and viewpoints are left with limited resources to mobilize following negative feedback. Moreover, sharing information that is known to all may be perceived as less valuable by members cognitively attuned to novel information. As such, it is unlikely to stimulate discussion and to be viewed as helpful to overcome the problems signaled by negative feedback. In the perceived absence of additional resources, negative feedback is unlikely to increase effort (Ilgen \& Davis, 2000). In sum, we propose that negative feedback enhances elaboration in informationally diverse (but not homogeneous) teams with negative feedback increasing teams' integrative efforts and informational diversity allowing members to contribute unique information to fuel these efforts.

Hypothesis 1a: Feedback valence and informational diversity interact in their effect on information elaboration: Negative (compared to positive) feedback has a positive effect on elaboration in diverse teams but not in homogeneous teams.

We further posit that by promoting elaboration, negative feedback also indirectly fosters creativity in informationally diverse but not homogeneous teams. We base this prediction on a combination of the outlined interaction of feedback valence and informational diversity on elaboration as well as on elaboration's established benefits for team creativity. Theoretically, knowledge integration as the conceptual core of elaboration, represents one core avenue to increased team creativity (van Knippenberg, 2017). Indeed, for teams to fulfill the hope of jointly achieving more creative outcomes than their members, requires members' mutual influence and interaction. Knowledge integration represents a crucial way of achieving this as it increases teams' chances of achieving higher novelty and usefulness through recombination. 
Prior research supports this reasoning that thoroughly processing and elaborating information promotes team creativity (e.g., Gong, Kim, Zhu, \& Lee, 2013; Li, Lin, Tien, \& Chen, 2015). Importantly, research further suggests that teams' active utilization and integration of information is more predictive of creativity than its mere availability or sharing (Hoever et al., 2012; Sung \& Choi, 2012). Given the key role of knowledge integration in promoting team creativity and the differential effects of feedback valence on informationally diverse and homogeneous teams' elaboration, we hence propose that negative feedback has a positive indirect effect on team creativity through elaboration in diverse but not in homogeneous teams.

Hypothesis 1b: Information elaboration mediates in the interactive effect of feedback valence and informational diversity on team creativity.

Positive feedback's benefits for informationally homogeneous teams. Whereas the effects of negative feedback better fit informationally diverse teams, the effects of positive feedback better match the informational foundation in homogeneous teams to promote generative processing. Generative processing involves members generating various ideas and solutions on the basis of each other's input. Variety can be generated in different ways including switches between semantic categories, linking weakly associated ideas, and pursuing a non-linear train of thought. Prior research supports the idea that positive feedback elicits positive affect (Ziller et al., 1962) which makes individuals use their own information more flexibly. Positive affect has been found to promote individuals' divergent thinking by helping them detect parallels between seemingly unrelated task elements and contexts (Bless \& Fiedler, 2006; Estrada et al., 1994) and to reduce members' attention to norms making them more likely to lead the discussion off on a tangent and share half-baked ideas (Williams, 2002; cf. Grawitch, Munz, Elliott, \& Mathis, 2003). Positive feedback, through its effect on positive affect, thus elicits divergent insights 
among individuals (Davis, 2009; De Dreu, Baas, \& Nijstad, 2008), which form important contributions to a team's generative processing as long as they are linked through an ongoing dialog in which members use each other's input as stepping stones for their own inputs.

Critically, this linkage of members' input is not equally likely to occur in all teams but builds on a team's shared knowledge base. First, a shared knowledge base ensures that members' divergent contributions relate to the other members' knowledge and thus stimulate new insights. Indeed, Dugosh and Paulus (2005) found that exposure to the ideas of others was more likely to elicit cognitive stimulation when these ideas were common (vs. highly unique). Second, it may put teams in a better position to relate to each other's divergent ideas. This creates opportunities for mutual enhancement (Wittenbaum et al., 1999) which reinforces members' attempts to share divergent thoughts. Informationally diverse teams, in turn, are not as well equipped to link each other's divergent ideas and thus to promote generative processing. Diversity may itself be a source of divergent insights (as unshared information may appear unusual or outside of the norm for others). Yet research has also found diversity to impair members' ability to build on each other's ideas (Harvey, 2013). Likewise, divergent insights that are formed based on unshared information may be difficult for the rest of the team to relate to. As ideas and information which are more difficult to relate to face a greater risk of being ignored, discounted, or rejected (Taggar, 2001; cf. Cruz, Boster, \& Rodriguez, 1997; Reber, Schwarz, \& Winkielman, 2004; Winkielman \& Cacioppo, 2001) they are less likely to feed into teams' generative processing. Moreover, positive feedback induces task-related positive affect (Ziller et al., 1962) and signals the absence of threats or problems. This has been shown to increase individuals' reliance on their own knowledge and approaches to the task (Bless \& Schwarz, 1999) leaving them less attuned to external novel information. This should be particularly detrimental for informationally 
diverse teams where one member's insights are less likely to relate to another's knowledge. Given prior studies which show that the ideas of others are more likely to spark new insights for individuals who deliberately attend to them (Dugosh et al., 2000), members of informationally diverse teams may thus be less likely to derive new insights from their teammates' input. Hence, we predict that positive feedback fosters generative processing in informationally homogeneous (but not diverse) teams because a team's shared knowledge base ensures that members' divergent contributions stimulated by positive feedback can be jointly harnessed.

Hypothesis 2a: Feedback valence and informational diversity interact in their effect on team generative processing: Positive (compared to negative) feedback has a positive effect on team generative processing in homogeneous teams but not in diverse teams. We further propose that by stimulating generative processing, positive feedback will indirectly also promote team creativity in informationally homogeneous but not diverse teams. This moderated mediation hypothesis builds on the proposed interaction of feedback and informational diversity on generative processing which we combine with arguments supporting the benefits of generative processing. Theoretically, generative processing represents the other major way for teams to achieve creative synergy - in this case by members stimulating each other to develop novel insights. Empirically supporting this notion, prior work attests to the creative benefits of generative processing in the sense of members not only making unique contributions but also linking them by building on each other's ideas (Harvey, 2013; 2014) and prompting teammates to consider new contexts (Brown et al., 1998) or frames of reference (Hargadon \& Bechky, 2006). Hence, we predict that positive feedback given to homogeneous teams should have a positive indirect effect on team creativity via generative processing.

Hypothesis 2b: Team generative processing mediates in the interactive effect between 
feedback valence and informational diversity on team creativity.

\section{The Joint Effect of Feedback Valence and Informational Diversity on Team Creativity}

In addition to proposing that informational diversity interacts with feedback valence in its effect on elaboration and generative processing as well as the indirect effects on team creativity through these processes, we also posit that feedback valence and informational diversity interact in their total effect on team creativity. This prediction builds on the moderated mediation predictions ( $\mathrm{H} 1 \mathrm{~b} \& \mathrm{H} 2 \mathrm{~b})$ but is not a direct corollary thereof. Indeed, as outlined by Rucker, Preacher, Tormala, and Petty (2011), the total effect of an (interaction of) independent variable(s) on a dependent variable and the (main or conditional) indirect effects through mediating variables are distinct effects. As such, the existence of indirect effects does not equal the existence of a total effect which may be affected by other, unmeasured mediators.

With regard to feedback valence's effect on team creativity there are arguments in support of a total effect of the feedback's interaction with informational diversity on team creativity. First, the knowledge-intensive and interdependent nature of team creativity renders the information processing mechanisms conceptually more proximal and hence more potent than other processes and emergent team states conceivably affected by feedback valence. For instance, positive feedback likely promotes positive affect among teammates, but positive affect alone has been found to not directly predict team creativity (Tsai, Chi, Grandey, \& Fung, 2012; Ziller et al., 1962). Likewise, positive feedback may elicit team potency - members' generalized belief about the team's capabilities (Miron-Spektor, Erez, \& Naveh, 2011) - or team creative efficacy - members' shared belief in their team's capacity to be creative (Shin \& Zhou, 2007). Yet the same research suggests that their effects are mixed (Miron-Spektor et al., 2011) and the theoretical arguments for their effectiveness often center around their potential to elicit and 
sustain elaboration and related information processing mechanisms (Shin \& Zhou, 2007; van Knippenberg, 2017). This is not to say that these other processes are unlikely to occur or play no role in the relation between feedback valence and team creativity; part of our argument for the effects of feedback valence builds on its effect on members' affect. It does suggest, however, that information processing mechanisms have more proximal and less contingent effects. Moreover, it implies that to the extent that positive affect or team creative efficacy are triggered by positive feedback, their impact is effectuated through these information processing mechanisms and subject to the contingency of teams' informational diversity. Hence, we propose the following:

Hypothesis 3: Informational diversity interacts with feedback valence to affect team creativity: Negative feedback has a positive effect on creativity in diverse (but not homogeneous) teams and positive feedback has a positive effect on creativity in homogeneous (but not diverse) teams.

So far, we have discussed elaboration and generative processing separately because they represent different routes to creativity with different informational foundations and combinatorial mechanisms that hail from different streams of the team creativity literature. Moreover, there are theoretical reasons to suggest that they are neither mutually necessary nor sufficient. Teams can share and integrate their information without prompting each other to generate new insights. Likewise, generative processing may occur without teams fully elaborating on and integrating different members' input. Yet in an ongoing discussion, these two processes may be related. Generative processing may prompt elaboration in an attempt to comprehend or integrate new content. Likewise, when elaboration and sharing unshared information occurs in teams in which members closely attend to each other, it may lead to cognitive stimulation (Dugosh et al., 2000) and generative processing. In fact, recent qualitative work suggests that creative project work in 
teams switches between integrating and de-integrating sequences which complement and elicit each other (Harrison \& Rouse, 2014). Thus, although we propose that elaboration and generative processing each are important mediators in the interactive effect of feedback and diversity on team creativity (see Figure 1 for our model), we do not expect them to be wholly unrelated.

Insert Figure 1 about here

METHODS

\section{Design and Participants}

We tested our hypotheses experimentally to be able to draw inferences about causality. The experiment had a 2 (informational diversity: diverse vs. homogeneous) x 2 (feedback valence: positive vs. negative) between-group design. A total of 234 students ( $49.6 \%$ female, mean age: $20.88, S D=2.11$ ) from a Dutch university were assigned to 78 three-person teams that were randomly assigned to experimental conditions. The majority of participants were business administration $(80.3 \%)$ or economics $(6.0 \%)$ students. They were compensated with 10 euro or course credit. We video-taped teams to allow for behavioral observation of the posited mediating mechanisms. The original sample contained 79 teams, but one team was excluded as the video-recording showed that they failed to follow the instructions. Due to technical problems, the video recording for one team was missing, reducing the sample size for all analyses involving video-coded measures to 77 teams. Because there is no reason to suspect that this team behaved differently than the other teams, we included their data in the analyses where possible.

\section{Experimental Task and Manipulations}

Task. The task was adapted from a creativity task used in prior research (Hoever et al., 2012) designed to observe teams while they devise a creative plan. Participants take on the roles 
of a team managing a theater which is charged with devising a creative action plan for the theater's future. First, participants individually studied role instructions and information about the theater (e.g., a schedule of plays, a floor plan). After this, they wrote down what they considered important to achieve with the plan and their initial ideas. For the team task, they were asked to develop a creative plan for the theater and given a definition of creativity as the joint novelty and usefulness of an idea. We asked them to submit one integrated plan and not a list of unconnected ideas. As motivation, monetary rewards were given to the most creative teams.

Informational diversity. Informational diversity was manipulated through functional role instructions paired with partially unshared information, in line with its definition as the extent to which members of a team differ in their task-relevant knowledge and perspectives. In diverse teams, members were assigned the roles of the Artistic, Event, and Finance Manager. Each role description stressed what was important for this manager and what members should ensure was realized in the final plan. The Artistic Director had to ensure high creative reputation, the Event Manager was concerned with service quality and community involvement, and the Finance Manager had to improve the financial performance. Participants also received information about the theater. Some information was shared across conditions (location plan, overview of target audiences). Other information was unshared in diverse but fully shared in homogeneous teams. This included a calendar of plays (Artistic Director), an overview of sales, prices, and revenues (Financial Manager), and a plan of the theater's facilities (Event Manager). This manipulation resembles the notion of functional assignment diversity in that different views and information arise from functional accountabilities rather than from experience (Bunderson \& Sutcliffe, 2002).

Our manipulation focused on the distribution of role-related perspectives and information between members. In practice, these distributional differences may entail a broader range of 
perspectives at the team level. With an experimental manipulation we can avoid confounding the distribution of differences with the amount or range of perspectives and information available to a team. Hence, previous studies on informational diversity (Homan et al., 2007) provided teams with equal amounts of information across conditions but manipulated its distribution. As a result, members of homogeneous teams have more information and viewpoints at their individual disposal than members of diverse teams. Parallel to this, we decided to keep the amount of information and perspectives constant at the team level. Hence, the homogeneous role contained the information and perspectives from all three diverse roles. Although distributing information across member is common in distributed information manipulations, our manipulation differs from these manipulations in three ways. First, for our open-ended task, shared and unshared information were equally vital for reaching a high quality solution. Second, the information distribution did not create a pre-discussion preference for a suboptimal solution. Third, we manipulated both differences in information and in perspectives.

Feedback valence. Building on prior work, feedback valence was manipulated with a feedback sheet that teams received mid-way through the task (Zhou, 1998). In line with our definition of feedback valence as the positivity or negativity of the discrepancy between a teams' creativity and the applied standards, the sheet was a printed form that informed the team how novel, useful, and overall creative their initial ideas were in comparison to others. For each dimension, it had a blank space in which the experimenter entered a number indicating the percentile rank a team ostensibly obtained with their initial ideas. When collecting the initial ideas, the experimenter told the teams that their ideas would be compared to the ideas from a prior study which had been rated by experts for their novelty, usefulness, and creativity so as to provide them with an indication of how creative their ideas were. This procedure of providing 
feedback in the form of a comparison against an interpersonal standard (i.e., prior teams' creativity) is in line with prior work on feedback valence and creativity (see e.g., Staw, 1974;

Zhou, 1998; Ziller et al., 1962). Moreover, it reflects the nature of creativity judgments which are inherently subjective and relative (George, 2007). In the negative feedback condition, teams were told that their ideas were more novel than the ideas of $20 \%$, more useful than $30 \%$, and more creative than $25 \%$ of the ideas developed by the teams in the prior study. Teams receiving positive feedback were informed that their ideas were more novel than $70 \%$, more useful than $80 \%$, and more creative than $75 \%$ of the ideas developed by the teams in the prior study. We chose these values based on prior work and a pilot test. As in prior experiments and to ensure the internal validity of our findings through randomization the feedback was bogus (i.e., it did not result from an actual evaluation of their ideas (e.g., Wofford \& Goodwin, 1990; Zhou, 1998)).

\section{Measures}

Creativity. Given our definition of team creativity as the joint novelty and usefulness of a final plan developed by interdependent actors as well as prior work which has argued that workplace creativity necessarily entails both novelty and usefulness (Zhou \& Shalley, 2011), we used the product of novelty and usefulness as an overall creativity indicator. Because plans consisted of one or multiple interrelated ideas, we separated each plan into its constituent ideas. Two independent coders coded each idea separately for novelty $(\operatorname{ICC}(1)=.69, \operatorname{ICC}(2)=.82$, mean $\left.r_{w g}=.89\right)$ and usefulness $\left(I C C(1)=.61, \operatorname{ICC}(2)=.76\right.$, mean $\left.r_{w g}=.88\right)$ on a seven-point scale ranging from " $1=$ not novel/useful at all" to " $7=$ very novel/useful". Given the stakeholder-dependent nature of usefulness judgments (George, 2007), we specified what usefulness meant in this context. Specifically, the coders assessed usefulness as the degree to which an idea addressed each of the three goals stated in the instructions (i.e., creative reputation, financial performance, 
community involvement and service levels). To form a team's creativity score we averaged each the product of novelty and usefulness of each idea included in a team's plan.

Information elaboration. Elaboration was coded from the videos in a different random order. As our hypotheses concern the interplay of feedback and diversity, we coded elaboration and generative processing for the post-feedback discussion. Two independent raters coded the extent to which teams engaged in the set of interrelated behaviors that define elaboration. In line with prior work (e.g., Hoever et al., 2012; van Ginkel \& van Knippenberg, 2008), teams received a score on a seven-point scale based on these coded behaviors $(\operatorname{ICC}(1)=.32, \operatorname{ICC}(2)=.47$, mean $\left.r_{w g j}=.86\right)$. We adapted this procedure from van Ginkel and van Knippenberg (2008) who used it to assess elaboration for teams solving a hidden-profile task. Specifically, we adapted the scale to make it viable for a task without a demonstrably correct answer and a situation in which different information pieces are not per se critical for finding a solution. Thus, rather than coding whether each critical piece of information was shared, discussed, and integrated, we coded whether teams shared the full range of their task-relevant information and perspectives, discussed these thoroughly, and integrated different pieces of information and perspectives. In line with elaboration's definition (van Knippenberg et al., 2004), the measure captured to which degree members engaged in behaviors that make up elaboration. A value of 1 reflects that teams directly began developing ideas with little or no systematic discussion of the different information and viewpoints. A score of 7 signifies that members fully shared and discussed the team's informational resources, elaborated and build on each other's information and perspectives, and attempted to integrate and combine them. The measure thus assigned the highest score to teams showing the full range of elaboration's interrelated sub-processes.

Generative processing. Generative processing was assessed as the frequency of 
statements verbalizing divergent thinking triggered by the input of other members. Coding focused on three types of statements. The first is members drawing parallels between the task's setting and other contexts to devise ideas as prompted by the previous input of another member. Example statements included the suggestion of service buttons like those found in airplanes following a teammate's suggestion to serve drinks at the seats. The second comprised members verbalizing their idea generation process by thinking aloud and sharing half-baked ideas in response to another member's suggestion. Third, we coded statements in which members took a previous utterance out of context and moved the discussion off on a tangent. Two independent coders noted the frequency of these behaviors which were summed to obtain an aggregated score $\left(I C C(1)=.38, I C C(2)=.54\right.$, mean $\left.r_{w g j}=.82\right)$. Elaboration and generative processing were coded separately to minimize influence of the one coding on the other.

Manipulation checks. To test the effectiveness of the feedback valence manipulation, we asked participants to assess the extent to which they perceived their team's ideas to be novel, useful, and creative relative to the ideas of other teams using an eight-item scale. For this scale, items used in prior studies manipulating feedback valence (Zhou, 1998) were adapted to the team context and amended to cover the different aspects of creativity that teams received feedback on. Example items included "Compared to other groups performing this task, our initial solutions were very creative" and answers were recorded on a five-point scale from " $1=$ not at all" to "5 = very much". The items formed a scale of high internal consistency $(\alpha=.95)$ and members showed high aggregate consistency $(\alpha=.97)$, agreement (mean $\left.r_{w g}=.96\right)$, and reliability $(I C C(1)=.77 ; \operatorname{ICC}(2)=.91)$ in their answers. This is in line with the intended team-level nature of the manipulation and justifies aggregating the responses to the team level (Bliese, 2000).

Our manipulation of diversity focused on the distribution of information and perspectives 
within teams. Whereas manipulating differences in members' information is straightforward such that we experimentally controlled which information members received, it is important to ascertain that members adopted their given perspectives and that these perspectives differed more between members of diverse than of homogeneous teams. To assess the teams' diversity of perspectives, two independent coders coded the members' individual answers to what they considered important for the team task for whether or not these statements reflected each of the three managerial perspectives (Artistic: $\kappa=.70$, Event: $\kappa=.76$, Finance: $\kappa=.81$ ). For each perspective, we calculated Blau's coefficient of heterogeneity as an indicator of the degree to which members differed in its endorsement. We averaged the three Blau coefficients across members to obtain a team-level score on which higher values reflect more diverse perspectives.

Alternative mediators. One of our core arguments is that the team-level effects of feedback valence are attributable to team information processing (elaboration and generative processing) rather than the affective and motivational mechanisms typically invoked in individual-level research. Hence, we measured these alternative mechanisms to test whether they account for the effects of feedback valence and to compare their indirect effects to those of elaboration and generative processing. Comparing the indirect effects through elaboration and generative processing to those through positive affect and team creative efficacy presents a stronger test of our theory than testing them against the mere absence of an effect (van de Ven, 2007). As their intrapsychic nature makes them hard to observe, we measured them with a postexperimental survey. For team creative efficacy we relied on a four-item scale from Tierney and Farmer (2002) originally designed for the individual level. As we wanted to assess members' beliefs in their team's creative ability, we changed the referent to the team (e.g., "I have confidence in my team's ability to solve problems creatively"; $\alpha=.87$ ). Following the logic of a 
referent shift model (Chan, 1998), satisfactory inter-rater reliability $(I C C(1)=.30 ; \operatorname{ICC}(2)=.57)$ and high inter-rater agreement $\left(r_{w g}=.92\right)$ justified aggregating the responses to the team level. Participants' current positive affect was assessed with ten items from the positive and negative affect schedule (Watson, Clark, \& Tellegen, 1988; $\alpha=.87$ ) and averaged to the team level.

\section{Procedure}

Upon arrival at the laboratory, participants were assigned to teams and informed that this study looked at the impact of feedback given on individual versus team ideas on the teams' creativity. In fact, all teams received feedback on the team's ideas. This cover story was adopted to provide participants with a rationale for the feedback procedure that did not reveal the real nature of the manipulation. During a first phase, participants individually studied their role instructions and information package. To ensure that they studied the material carefully and to support the cover story, they were asked to individually answer what they considered important to achieve and to write down their initial individual ideas. After 20 minutes, the experimenter started the team task during which teams needed to develop an action plan for the theater. Teams were informed that they would have 30 minutes to develop their plan but that the experimenter would collect their ideas after ten minutes and asked to record their ideas for the plan for the purpose of receiving feedback. When the experimenter collected these ideas, teams were given a piece of paper and asked to continue working while the experimenter checked their ideas. After a few minutes the experimenter returned and gave the teams the feedback sheet, the initial ideas, and a form for the team to record their final plan. Teams were asked to jointly review the feedback and come up with a final plan that was as creative as possible. After receiving the feedback, teams had 15 minutes to complete their plan. Finally, participants completed a brief post-experimental survey containing the manipulation checks, socio-demographic questions, and 
some additional measures. Each session lasted one hour at the end of which the experimenter debriefed and thanked participants and paid them or awarded their course credit.

\section{RESULTS}

\section{Descriptive Statistics and Correlations}

Table 1 displays the descriptive statistics and correlations. The mediators elaboration $\left(r_{\text {partial }}=.38, p<.001\right)$ and generative processing $\left(r_{\text {partial }}=.45, p<.001\right)$ were positively correlated with team creativity and with each other $\left(r_{\text {partial }}=.36, p<.001\right)$. So as to test the joint effect of our manipulations on elaboration (Hypothesis 1a), generative processing (Hypothesis 2a), and creativity (Hypothesis 3) we conducted analyses of variance (ANOVAs). For all hypotheses about (conditional) indirect effects, we relied on Hayes' (2013) procedure.

Insert Table 1 about here

\section{Manipulation Checks}

Feedback valence. In line with the manipulation's intended effect, an ANOVA testing for the effects of the feedback and diversity manipulation on the feedback valence manipulation check yielded a significant main effect of feedback valence as the only significant effect $(F(1$, 74) $\left.=640.39 ; p<.001, \eta^{2}=.89\right)$. Teams in the positive feedback condition reported significantly higher values $(M=4.06, S D=0.26)$ than teams in the negative condition $(M=2.26$, $S D=0.36)$. Moreover, the observed means significantly differed from the theoretical midpoint of the scale $(3)$ for both the negative condition $(t(37)=-12.59, p<.001)$ and the positive condition $(t(39)=26.12, p<.001)$. This suggests that the manipulation produced significant differences between the conditions and significant differences compared to the neutral midpoint of the scale. Neither the main effect for diversity $(F(1,74)=1.56 ; p=.22)$ nor the interaction between 
diversity and feedback $(F<1)$ was significant. Together, these results show that our feedback valence manipulation was successful and led participants in the negative feedback condition to see their ideas as less novel, useful, and creative than participants in the positive condition.

Diversity. We subjected the average Blau's index of the heterogeneity with which members of a team endorsed the different viewpoints to an ANOVA testing for the effects of feedback and diversity. This analysis yielded a significant main effect of diversity with higher heterogeneity in diverse $(M=0.43, S D=0.03)$ than in homogeneous teams $(M=0.19, S D=$ $\left.0.13, F(1,74)=114.15, p<.001, \eta_{\mathrm{p}}^{2}=.61\right)$ as the only significant effect (all other $\left.F s<1\right)$. This pattern of results also held for each separate Blau coefficient corresponding to each perspective indicating that our diversity manipulation succeeded in inducing more diverse viewpoints.

\section{Test of Hypotheses}

The effect of feedback and diversity on elaboration. Hypothesis 1a posits a positive effect of negative feedback on elaboration in diverse but not in homogeneous teams. An ANOVA testing for the effect of feedback and diversity on elaboration showed no significant difference between teams' elaboration in the negative $(M=3.44, S D=1.29)$ and positive feedback condition $(M=3.30, S D=1.00 ; F<1)$. There was, however, a significant main effect of diversity $\left(F(1,73)=6.27, p=.01, \eta^{2} \mathrm{p}=.08\right)$ with higher elaboration in diverse $(M=3.62$, $S D=1.32)$ than in homogeneous teams $(M=3.13, S D=0.90)$. Importantly, this effect was qualified by a significant feedback $x$ diversity interaction $\left(F(1,73)=38.95, p<.001, \eta_{\mathrm{p}}^{2}=.35\right)$. Planned contrasts revealed the predicted negative simple main effect of feedback valence in the diverse condition $\left(F(1,73)=23.44, p<.001, \eta^{2}{ }_{\mathrm{p}}=.24\right)$ : Diverse teams showed more elaboration following negative feedback $(M=4.34, S D=1.12)$ than following positive feedback $(M=2.87$, $S D=1.11)$. For homogeneous teams, there was a positive simple main effect of feedback valence 
on elaboration $\left(F(1,73)=15.78, p<.001, \eta_{\mathrm{p}}^{2}=.18\right)$, with homogeneous teams showing higher levels of elaboration following positive feedback $(M=3.66, S D=0.76)$ than negative feedback $(M=2.49, S D=0.61)$. The significant interaction and the pattern of simple main effects support Hypothesis 1a. An analysis of the interaction effect also qualified the observed diversity main effect. Diversity had a positive simple main effect on elaboration in the negative feedback condition with diverse teams engaging in more elaboration than homogeneous teams $(F(1,73)$ $\left.=36.98, p<.001, \eta_{\mathrm{p}}^{2}=.34\right)$. Yet in the positive feedback condition, diverse teams showed lower levels of elaboration than homogeneous teams $\left(F(1,73)=7.23, p=.01, \eta^{2}{ }_{p}=.09\right)$. Hence, the main effect of diversity is solely attributable to the higher levels of elaboration for diverse teams receiving negative feedback thus reflecting prior theory and findings that diversity does not automatically promote elaboration (Hoever et al., 2012; van Knippenberg et al., 2004) ${ }^{1}$.

The effect of feedback and diversity on generative processing. We conducted an ANOVA testing the effects of feedback valence and diversity on generative processing to assess the differential effects of positive feedback in homogeneous teams (Hypothesis 2a). Neither main effect was significant (both $F<1$ ) but the analysis yielded a significant interaction between feedback and diversity $\left(F(1,73)=21.80, p<.001, \eta_{\mathrm{p}}^{2}=.23\right)$. Planned contrasts revealed the predicted positive main effect of feedback valence on generative processing in homogeneous teams $\left(F(1,73)=11.46, p<.01, \eta^{2}{ }_{\mathrm{p}}=.14\right)$ : Teams showed higher generative processing in the positive $(M=3.49, S D=2.38)$ than in the negative feedback condition $(M=1.50, S D=0.97)$. In contrast, for diverse teams, positive feedback led to less generative processing $(M=1.65, S D=$ 1.77) than negative feedback $\left(M=3.60, S D=1.84 ; F(1,73)=10.38, p<.01, \eta_{\mathrm{p}}^{2}=.12\right)$.

\footnotetext{
${ }^{1}$ Indeed an ANOVA of teams' pre-feedback elaboration showed no significant diversity effects.
} 
Although we did not a priori expect a negative effect of positive feedback on generative processing in diverse teams, the finding that positive feedback has a positive effect on generative processing for homogeneous (but not diverse) teams and that generative processing is higher in homogeneous teams following positive feedback support our initial reasoning and Hypothesis $2 \mathrm{a}$.

The effect of feedback valence and diversity on team creativity. We conducted an ANOVA to test the predicted interaction of feedback valence and informational diversity on team creativity (Hypothesis 3$)$. The results showed that diverse $(M=16.09, S D=6.77)$ and homogeneous teams $(M=13.98, S D=7.37)$ did not significantly differ in their creativity ( $F(1$, $74)=2.77, p=.10)$. Likewise, the creativity of teams receiving negative $(M=14.04, S D=6.59)$ and positive feedback $(M=15.88, S D=7.57)$ was comparable $(F(1,74)=1.31, p=.26)$. Critically, the analysis yielded a significant feedback x diversity interaction $(F(1,74)=23.03$; $\left.p<.001 ; \eta^{2} \mathrm{p}=.24\right)$. Planned contrasts revealed the predicted negative simple main effect of feedback valence for diverse teams. They devised more creative plans after receiving negative feedback $(M=18.60, S D=6.26)$ than after positive feedback $(M=13.44, S D=6.41$; $\left.F(1,74)=6.37, p=.01, \eta^{2}{ }_{p}=.08\right)$. Conversely, for homogeneous teams, there was a positive simple main effect of feedback valence with homogeneous teams receiving positive feedback developing significantly more creative plans $(M=17.87, S D=7.99)$ than those receiving negative feedback $\left(M=9.48, S D=2.50 ; F(1,74)=18.57, p<.001, \eta^{2} \mathrm{p}=.20\right)$. The significant interaction as well as the pattern of simple main effects (see Figure 2) support Hypothesis 3.

Insert Figure 2 and 3, and Table 2 about here

The mediating role of elaboration and generative processing. To test the conditional indirect effects of feedback valence on creativity through elaboration and generative processing 
in diverse and homogeneous teams (Hypotheses $1 b \& 2 b$ ), we relied on a procedure by Hayes (2013) which offers a combined test of moderated mediation through multiple mediators. The specified model allowed for the moderation of the first stage of the indirect effects but constrained the effects from each mediator on creativity to be equal for homogeneous and diverse teams (see Model 8, Hayes, 2013). Within this procedure, estimates for the paths of the model are obtained using OLS regression analyses (see Table 2 and Figure 3) and the magnitude of the indirect effects is tested using bias-corrected confidence intervals constructed on the basis of 1000 bootstrap samples drawn from the original sample. Coefficients are considered significant if the respective $95 \%$ confidence interval excludes zero. Following his suggestions, we mean-centered the mediators and dummy coded diversity and feedback with the homogeneous and the negative feedback condition as the zero-coded reference categories.

Mirroring the results for the tests of Hypotheses 1a and 2a, there was a significant effect of the feedback x diversity interaction on elaboration $(b=-2.63, S E=0.42, t=-6.24, p<.001)$ and generative processing, $(b=-3.95, S E=0.85, t=-4.67 p<.001)$. Regressing creativity on feedback, diversity, their interaction, and the two mediators yielded a model that explained significant variance in team creativity (adjusted $R^{2}=.41, p<.001$ ). In this model, elaboration $(b=1.71, S E=0.74, t=2.30, p=.02)$ and generative processing ${ }^{2}(b=1.22, S E=0.37, t=3.29$

\footnotetext{
${ }^{2}$ We argued that generative processing is more than idea generation as it consists of members providing
} divergent input and triggering each other to produce new input. To empirically test this, we video-coded the number of distinct ideas generated by teams. The number of ideas was positively related to generative processing $\left(r_{\text {partial }}=.51\right)$, but unrelated to creativity $\left(r_{\text {partial }}=-.04\right)$. Likewise, it did not mediate the effect of feedback on creativity in diverse $(b=0.31, S E=0.83, C I[-1.39 ; 1.98])$ or homogeneous teams $(b=-0.06, S E=0.28, C I[-1.15 ; 0.22])$. As such generative processing and idea generation are related, but have distinct effects. 
$p<.01)$ were the only significant predictors, rendering the effect of the interaction between feedback valence and diversity non-significant $(b=-4.16, S E=3.18, t=-1.31 p=.19)$.

Hypotheses $1 \mathrm{~b}$ and $2 \mathrm{~b}$ predicted elaboration and generative processing to mediate the interaction effect. In support, there was an indirect feedback x diversity interaction on creativity through elaboration $(b=-4.50, S E=2.06, \mathrm{CI}[-9.06 ;-0.87])$ and generative processing $(b=-$ 4.82, $S E=2.55, \mathrm{CI}[-11.54 ;-1.12])$. To illustrate this multiple mediated moderation effect we calculated the conditional indirect effects of feedback valence through each of the mediators for each level of diversity. The results show the hypothesized negative indirect effect of feedback valence (i.e., a relative benefit of negative feedback) on creativity for diverse teams through elaboration $(b=-2.51, S E=1.29, \mathrm{CI}[-5.59 ;-0.48])$ and a positive indirect effect on creativity (i.e., a relative benefit of positive feedback) through elaboration for homogeneous teams ( $b=$ $1.99, S E=0.89, \mathrm{CI}[0.47 ; 3.97])$. Moreover, we found the expected positive indirect effect of feedback valence on creativity through generative processing in homogeneous teams $(b=2.43$, $S E=1.37, \mathrm{CI}[0.43 ; 5.85])$. In addition, there was a negative effect of feedback valence through generative processing for diverse teams $(b=-2.39, S E=1.41$, CI $[-6.69 ;-0.48]){ }^{3}$ These results support our proposition that different processes account for the differential effects of feedback valence on the creativity of diverse and homogeneous teams. Below we discuss the implications of our findings and potential post-hoc explanations for the effect of feedback valence on generative processing in diverse teams that was not only not positive but negative.

${ }^{3}$ To ensure that the observed indirect effects were not due to the inclusion of the other mediator, we re-ran our analyses for each mediator separately. This did not change the pattern or significance of the indirect effects. We also tested whether our model predicted novelty and usefulness as the two dimensions of creativity. Results for each component as the dependent variable converged highly with those obtained for overall creativity. 


\section{Exploratory analyses}

Our results support our hypotheses, but also raise a set of questions that we addressed with additional analyses. First, we find that in homogeneous teams, positive feedback is linked to higher generative processing and elaboration whereas in diverse teams, negative feedback is linked to higher elaboration and generative processing. This raises the question of what drives the effect (e.g., does negative feedback increase elaboration in diverse teams or does positive feedback depress it?) ${ }^{4}$. To answer this question, we coded both processes prior to the feedback and tested whether positive and negative feedback caused a change in these processes for different teams. We conducted an ANOVA with diversity and feedback as between-team factors and time (pre- vs. post-feedback) as a within-team factor. In line with our rationale, this analysis yielded a significant three-way interaction of feedback, diversity, and time, indicating that positive and negative feedback differentially changed elaboration in diverse and homogeneous teams $(F(1,73)=23.97, p<.001)$. After receiving negative feedback, diverse teams engaged in higher elaboration than prior to the feedback $\left(M_{\text {pre }}=3.64\right.$ vs. $M_{\text {post }}=4.34, F(1,73)=9.61, \mathrm{p}<$ $.01)$. In contrast, elaboration decreased for diverse teams after positive feedback $\left(M_{\mathrm{pre}}=3.57 \mathrm{vs}\right.$. $\left.M_{\text {post }}=2.87, F(1,73)=8.98, p<.01\right)$ and for homogeneous teams after negative feedback $\left(M_{\text {pre }}=\right.$ 3.41 vs. $\left.M_{\text {post }}=2.49, F(1,73)=15.49, p<.01\right)$, and remained unchanged for homogeneous teams receiving positive feedback $\left(M_{\text {pre }}=3.76\right.$ vs. $\left.M_{\text {post }}=3.66, F(1,73)<1\right)$. A parallel analysis also yielded a significant three-way interaction of diversity, feedback, and time on generative processing $(F(1,73)=13.36, p<.001)$. A comparison of the effects of time across conditions showed that homogeneous teams' generative processing increased following positive feedback

\footnotetext{
${ }^{4}$ We would like to thank an anonymous reviewer for raising this excellent point.
} 
$\left(M_{\text {pre }}=2.48\right.$ vs. $\left.M_{\text {post }}=3.49, F(1,73)=4.05, p<.05\right)$ but did not change after negative feedback $\left(M_{\text {pre }}=2.24\right.$ vs. $\left.M_{\text {post }}=1.50, F(1,73)=1.73, p=.19\right)$. In turn, positive feedback did not change diverse teams' generative processing $\left(M_{\text {pre }}=1.75\right.$ vs. $\left.M_{\text {post }}=1.65, F(1,73)<1\right)$, whereas negative feedback increased it $\left(M_{\text {pre }}=1.51\right.$ vs. $\left.M_{\text {post }}=3.60, \mathrm{~F}(1,73)=14.99, \mathrm{p}<.001\right)$.

Second, our theorizing emphasizes that the effects of feedback valence are effectuated through different mechanisms than those operating at the individual level. Our analyses show the predicted conditional indirect effects of elaboration and generative processing. However, given that our theorizing stresses the comparative size of our effects vis-à-vis the processes identified in prior research, we decided to empirically compare the indirect effects through elaboration and generative processing with these theoretical alternatives. This represents a stronger test of our theory than the mere test against absence of an effect (van de Ven, 2007). Hence, we tested the mediating effects of positive affect and team creative efficacy as well as the relative size of their indirect effects compared to those associated with elaboration and generative processing. These analyses showed that positive affect did not mediate the effects of feedback valence in the homogeneous ( $b=0.51, S E=0.76$, CI $[-.70 ; 2.34])$ nor in the diverse condition $(b=0.28, S E=0.49$, CI $[-.27 ; 1.75])$. Likewise, team creative efficacy did not did not mediate the effects of feedback valence on creativity in homogeneous ( $b=-0.43, S E=1.06$, CI [-2.40; 1.81$])$ nor in diverse teams $(b=-0.29, S E=0.74, \mathrm{CI}[-1.98 ; 1.08])$. Finally, we tested whether the indirect effects of the feedback $x$ diversity interaction on team creativity through elaboration and generative processing where stronger than those associated with the alternative mediators. In line with our theory these analyses showed that the indirect effects through elaboration (Contrast: $c=4.62, S E=1.98, \mathrm{CI}$ [1.40; 9.57]) and through generative processing (Contrast: $c=5.76, S E=2.81, \mathrm{CI}[2.01 ; 13.77])$ were significantly stronger than the indirect effect through team creative efficacy. Likewise, the 
indirect effect of the interaction through elaboration (Contrast: $c=5.69, S E=2.63$, CI [1.01; 11.71]) and generative processing (Contrast: $c=6.19, S E=3.18, \mathrm{CI}[1.76 ; 14.53])$ respectively were significantly stronger than the one associated with positive affect.

\section{DISCUSSION}

We found that feedback valence and informational diversity interacted to affect team creativity. Each type of feedback, when matched with the right level of informational diversity, increased creativity through one of two alternative information processing routes propagated by different streams of the team information processing literature on team creativity. Negative feedback promoted team creativity through elaboration when teams were informationally diverse whereas positive feedback enhanced creativity through generative processing when given to homogeneous teams. Our study provides important theoretical and practical insights.

\section{Theoretical Implications}

Starting from a conceptual consideration of what differentiates team from individual creativity - its roots in the interdependent actions of multiple members (Gilson \& Shalley, 2004) - and what embodies its greatest promise - the synergistic use of members' knowledge and views (e.g., Harvey, 2014) - we develop and test team-specific theory. Given team creativity's conceptual characteristics, we base our model on the teams as information processors lens (Hinsz et al., 1997) which we use to integrate two parallel but so far largely disconnected views on how team information processing promotes team creativity. This integration offers key insights for the team information processing lens. And regarding the question of how the widely-used managerial tools of positive and negative feedback affect the prized outcome of team creativity, this lens points to a novel set of mechanisms and contingency factors that are germane to teams.

Implications for the team information processing perspective on team creativity. The 
first core implication of our analysis of feedback valence's effect on team creativity is that we break new ground within the dominant theoretical lens on team creativity. Team information processing is known to be vital for team creativity (Anderson et al., 2014; Hülsheger et al., 2009; van Knippenberg, 2017). Yet different streams of this literature consider distinct information processing mechanisms as important. Research grounded in the brainstorming tradition focuses on generative processing (Nijstad et al., 2003) and work rooted in the team performance literature hails elaboration as the central route to team creativity (van Knippenberg, 2017). Bringing these two routes together in service of answering our core research question and analyzing them through the teams as information processors lens exposes their systematic differences in terms of combinatorial processes (trigger vs. integration) and informational foundations (shared knowledge base vs. different information and perspectives).

Importantly, this in-depth understanding is not just an end in itself. Instead, it moves our knowledge of how team information processing boosts team creativity from a place where we lack a systematic understanding of the relative importance of these two routes to the insight that both have an important role to play in team creativity, but emerge from different combinations of antecedents. Given that we find parallel benefits of elaboration and generative processing for team creativity, this raises the question of how to model their interplay. Although more followup work is needed, one of our results points to the promise of this endeavor. Specifically, we find that negative feedback raised the creativity of diverse teams through elaboration and generative processing (with sensitivity analyses showing significant pre- to post-feedback increases for both processes in diverse teams). A possible explanation may be that in diverse teams receiving negative feedback, elaboration itself triggers generative processing as members are exposed to and attend to the unshared information of others (e.g., Nijstad et al., 2003). A comparison of the 
processes' correlation across conditions offers provisional support for this conjecture. Sharing and discussing unshared information (a core part of elaboration) is strongly related to generative processing in diverse $(r=.60, p<.001)$ but not homogeneous teams $(r=.11, p=.50)$ in which all members hold this information.

Moreover, our account adds to the teams as information processors model (Hinsz et al., 1997) which made seminal contributions to the teams literature by systematically comparing team to individual information processing and compiling a list of factors that influence it. Our account adds to this by building specific theory about the interplay of some of these factors. The resultant insight that the effects of the interventions of positive and negative feedback hinge on teams' informational diversity also raises exciting possibilities for further research on other interventions and their effect on team information processing. Although a growing number of studies attests to the value of external interventions in aiding team information processing (Fisher, 2017; Okhuysen \& Eisenhardt, 2002; Zellmer-Bruhn, 2003), few studies have explored how the effectiveness varies as a function of team characteristics such as team diversity.

Implications for research on feedback valence and team creativity. Importantly, our model also contributes to the literature on the relation between feedback valence and team creativity. First, applying the team information processing lens to the question of how feedback valence affects team creativity leads to the insight that the answer does not lie in a positive main effect like the one found at the individual level (Zhou, 2008). Rather, it suggests the need to adopt a contingency view that acknowledges that the valence of the feedback needs to match the team's informational diversity. Identifying informational diversity as a contingency factor of feedback valence's effect on team creativity advances the sparse existing research which found inconclusive results for this effect (Ziller et al., 1962). Our results suggest that one reason for this 
may be that this research did not differentiate between teams' varying levels of informational diversity. For future research, this raises the question which other contingencies affect this effect. One promising avenue to explore is whether external informational resources (e.g., provided by leaders, retrieved from knowledge management systems, or via boundary-spanning activities) can fulfill similar functions as the additional informational resources held within diverse teams.

Second, our model represents a theoretical shift in the mechanisms that underlie feedback valence effects on creativity. Prior work has largely relied on motivational states (e.g., mastery perceptions; Zhou, 1998) and positive affect (e.g., Fodor \& Greenier, 1995; Ziller et al., 1962) as mechanisms to explain the creative benefits of positive feedback (Zhou, 2008). This logic is echoed by Zhou and Shalley's (2011) review of feedback as a factor that affects creativity through motivational mediators. In contrast, our results show that positive and negative feedback exert their effects on team creativity through the information processing routes of elaboration and generative processing even after controlling for positive affect and team creative efficacy. This emphasizes the primacy of team processes compared to aggregated individual states as drivers of team creativity, and with it the value of shifting to a team information processing lens.

This insight also offers exciting future research ideas, such as the interplay between team information processing and team affective and motivational emergent states. Research suggests that information processing is closely linked to affect and motivation (Bless \& Fiedler, 2006; De Dreu, Nijstad, \& van Knippenberg, 2008). Indeed, our model assumes that feedback valence partially exerts its effects on team information processing through member affect. Empirically studying this dynamic relation is an intriguing future research challenge. Finally, because the benefits of elaboration have also been shown for team performance (Kearney \& Gebert, 2009) and decision-making (van Ginkel \& van Knippenberg, 2008), it is possible that our findings on 
the benefits of negative feedback for diverse teams extend to other tasks. Prior research shows that external interventions affect team processes (e.g., Okhuysen \& Eisenhardt, 2002). Yet no prior work tested the differential impact of feedback on diverse and homogeneous teams. Our work identifies this as a fascinating avenue for future studies.

\section{Limitations and Directions for Future Research}

These implications should be viewed in light of certain limitations and questions for future research. First, we tested our hypotheses experimentally to allow inferences about causality and to observe team process rather than rely on retrospective self-assessment (Weingart, 1997). External validity is rarely an aim of experiments (Mook, 1983). Yet one might ask whether our findings generalize to other settings. Lacking data from systematic replications, prior research may offer provisional answers. Meta-analyses of a range of effects in psychology (Anderson, Lindsay, \& Bushman, 1999), organizational behavior (Colquitt, 2014), and the specific factors of feedback (Kluger \& DeNisi, 1996) and diversity (van Dijk, van Engen, \& van Knippenberg, 2012) show high convergence between lab and field findings. This bolsters our confidence that our findings may hold beyond our study, but follow-up work remains desirable.

Second, we manipulated feedback valence by assigning teams randomly to feedback conditions. This ensures high internal validity, but may raise the question of how participants perceived the feedback. Creativity judgments are inherently subjective and self- and other-rated creativity have been found to diverge (Kurtzberg, 2005) suggesting that one's own creativity may be hard to assess. Both behavior coders paid close attention to teams voicing doubts about the feedback. For four teams (one per condition) a coder made such a cautionary note. Sensitivity analyses excluding these teams yielded identical patterns of effects. Still, one may ask whether our findings extend to situations in which teams receive feedback that is based on their actual 
creativity. Prior work observing diverse teams across multiple tasks involving repeated feedback (Watson, Kumar, \& Michaelsen, 1993) found them to improve their performance (including their creative performance) from initially low levels to higher levels at later stages. This provides indirect evidence that actual performance-based negative feedback can enhance creativity. Research also shows that the credibility of feedback accentuates the effects of feedback valence (Podsakoff \& Farh, 1989). Hence, if teams tacitly doubted feedback credibility, our findings might prove to be conservative estimates of its effects. Still, future studies that explore the effects of (non-random) positive and negative feedback on teams are needed to corroborate this.

Third, our feedback was given during an ongoing task and its effects may not fully compare to those of studies that look at how feedback on a completed task affects teams' creativity on subsequent tasks. Individual-level research suggests that repeated success on prior projects makes inventors overly reliant on their prior recipe for success and reduce their creativity on future projects (Audia \& Goncalo, 2007). Whether the observed effects of feedback on team creativity are similarly time-sensitive needs to be established through future studies.

Fourth, our results stem from teams with certain characteristics. Specifically, our teams are low in authority differentiation and temporal stability and range from low to moderate in skill differentiation (with diverse teams having unique knowledge and views but not long-held expert roles; Hollenbeck, Beersma, \& Schouten, 2012). Future research needs to establish whether our findings hold for teams that differ along these dimensions. For instance, in temporally more stable teams, prior history may affect their reaction to feedback. Repeated negative feedback might reduce its initial positive effect by creating negative diversity mindsets (van Knippenberg, van Ginkel, \& Homan, 2013) or harmful stress (Byron, Khazanchi, \& Nazarian, 2010).

Finally, we manipulated the teams' informational diversity directly rather than use 
another diversity attribute (e.g., gender) as a proxy. This choice driven by our theory which stresses the impact of members holding shared (vs. unshared) information and perspectives. Future research should test how feedback valence affects the creativity of teams diverse on other attributes. Many attributes may, depending on the task, afford teams with diverse informational resources. Yet team diversity can also prompt social categorization and the formation of subgroups. In this situation, negative feedback may function as an identity threat and harm rather than promote elaboration (van Knippenberg et al., 2004). Finally, our sample size - although in keeping with prior team studies (Shen et al., 2011) - might raise concerns about power. This is unlikely to account for our significant effects. Yet it raises the question whether our analyses miss potentially smaller effects and makes a replication with a larger sample desirable.

\section{Practical Implications}

Focusing on the team-specific implications of feedback valence for creativity also yields valuable recommendations for managers seeking to boost team creativity. First, our finding that specific combinations of feedback valence and informational diversity are particularly beneficial for team creativity suggests that managers might want to take the nature of their team into account when considering what feedback to give to their teams. Seemingly reflecting earlier individual-level research on feedback and creativity, Egan (2005) found that leaders of diverse teams strongly espoused reinforcing successes but cautioned against external pressures and negative information. Our results question whether this is a universally favorable strategy as we show that negative feedback can boost creativity in informationally diverse teams by prompting them to better explore and integrate members' informational resources. For these teams, it may thus be advisable to complement positive feedback with information about what needs to be improved. Yet when providing feedback to informationally homogeneous teams with shared 
knowledge and views, managers might want to stress the positive aspects of a team's creativity and pair necessary negative feedback with information on positive achievements.

Naturally, although managers can tailor the feedback messages somewhat in light of the team's informational diversity, feedback valence is usually determined by a team's creativity. As such, managers may need to provide a team with feedback that is not an optimal fit with its informational diversity. For these situations, our findings concerning the two information processing routes that underlie feedback valence's effect and their antecedents form the basis for advice on how to best support teams. For informationally diverse teams given positive feedback, this might include prompting the sharing and integration of unshared information or stimulating the creation of a shared knowledge base which may allow diverse teams to show more generative processing. Likewise our results point to the value of trying to nurture generative processing in homogeneous teams following negative feedback or providing them with novel information so as to give them the resources they otherwise lack to engage in elaboration. Thus, our results inform practice in terms of which forms of feedback might prove effective for which teams and how to support teams if the situation requires feedback that might otherwise be a suboptimal fit.

\section{CONCLUSION}

Team creativity is considered important for organizations and managing for creativity is a key managerial challenge. Yet to date, our understanding of how teams react to and benefit creatively from external feedback is limited. We provide important first insights into how the effects of feedback valence at the team level differ contingent on teams' informational diversity. Our findings support an account in which feedback valence and team informational diversity need to match to allow teams to optimally contribute and combine their members' resources to produce collective information processing patterns that ultimately benefit their joint creativity. 


\section{REFERENCES}

Amabile, T. M. 1996. Creativity in context: Update to the Social Psychology of creativity. Boulder, CO: Westview Press.

Anderson, C. A., Lindsay, J. J., \& Bushman, B. J. 1999. Research in the psychological laboratory: Truth or triviality? Current Directions in Psychological Science, 8: 3-9.

Anderson, N., Potocnik, K., \& Zhou, J. 2014. Innovation and creativity in organizations: A stateof-the-science review, prospective commentary, and guiding framework. Journal of Management, 40: 1297-1333.

Audia, P. G., \& Goncalo, J. A. 2007. Past success and creativity over time: A study of inventors in the hard disk drive industry. Management Science, 53: 1-15.

Barsh, J., Capozzi, M. M., \& Davidson, J. 2008. Leadership and innovation. McKinsey Quarterly, 36-47.

Bless, H., \& Fiedler, K. 2006. Mood and the regulation of information processing and behavior. In J. P. Forgas (Ed.), Affect in social thinking and behavior: 65-84. New York: Psychology Press.

Bless, H., \& Schwarz, N. 1999. Sufficient and necessary conditions in dual-process models: The case of mood and information processing. In S. Chaiken \& Y. Trope (Eds.), Dual-process theories in Social Psychology: 423-440. New York: Guilford Press.

Bliese, P. D. 2000. Within-group agreement, non-independence, and reliability: Implications for data aggregation and analysis. In K. J. Klein \& S. W. J. Kozlowski (Eds.), Multilevel theory, research, and methods in organizations: 347-381. San Francisco: Jossey-Bass.

Bohner, G., Bless, H., Schwarz, N., \& Strack, F. 1988. What triggers causal attributions? The impact of valence and subjective probability. Eurpean Journal of Social Psychology, 18: 335-345.

Brendl, C. M., \& Higgins, E. T. 1996. Principles of judging valence: What makes events positive or negative? Advances in Experimental Social Psychology, 28: 95-160.

Brown, V., Tumeo, M., Larey, T. S., \& Paulus, P. B. 1998. Modeling cognitive interactions during group brainstorming. Small Group Research, 29: 495-526.

Bunderson, J. S., \& Sutcliffe, K. M. 2002. Comparing alternative conceptualizations of functional diversity in management teams: Process and performance effects. Academy of Management Journal, 45: 875-893.

Byron, K., Khazanchi, S., \& Nazarian, D. 2010. The relationship between stressors and creativity: A meta-analysis examining competing theoretical models. Journal of Applied Psychology, 95: 201-212.

Campbell, D. T. 1960. Blind variation and selective retentions in creative thought as in other knoweldge processes. Psychological Review, 67: 380-400.

Chan, D. 1998. Functional relations among constructs in the same content domain at different levels of analysis: A typology of composition models. Journal of Applied Psychology, 83: 234-246.

Colquitt, J. A. 2014. Lab vs. field OB: Do findings converge? CARMA Webcast.

Cruz, M. G., Boster, F. J., \& Rodriguez, J. I. 1997. The impact of group size and proportion of shared information on the exchange and integration of information in groups.

Communication Research, 24: 291-313.

Davis, M. A. 2009. Understanding the relationship between mood and creativity: A metaanalysis. Organizational Behavior and Human Decision Processes, 108: 25-38. 
De Dreu, C. K. W., Baas, M., \& Nijstad, B. A. 2008. Hedonic tone and activation level in the mood-creativity link: Toward a dual pathway to creativity model. Journal of Personality and Social Psychology, 94: 739-756.

De Dreu, C. K. W., Nijstad, B. A., \& van Knippenberg, D. 2008. Motivated information processing in group judgment and decision making. Personality and Social Psychology Review, 12: 22-49.

Dugosh, K. L., \& Paulus, P. B. 2005. Cognitive and social comparison processes in brainstorming. Journal of Experimental Social Psychology, 41: 313-320.

Dugosh, K. L., Paulus, P. B., Roland, E. J., \& Yang, H.-C. 2000. Cognitive stimulation in brainstorming. Journal of Personality and Social Psychology, 79: 722-735.

Egan, T. M. 2005. Creativity in the context of team diversity: Team leader perspectives. Advances in Developing Human Resources, 7: 207-225.

Estrada, C., Isen, A. M., \& Young, M. J. 1994. Positive affect influences creative problem solving and reported source of practice satisfaction in physicians. Motivation and Emotion, 18: 285-299.

Fisher, C. M. 2017. An ounce of prevention or a pound of cure? Two experiments on in-process interventions in decision-making groups. Organizational Behavior and Human Decision Processes, 138: 59-73.

Florida, R., \& Goodnight, J. 2005. Managing for creativity. Harvard Business Review, 83(7/8): 124-131.

Fodor, E. M., \& Greenier, K. D. 1995. The power motive, self-affect, and creativity. Journal of Research in Personality, 29: 242-252.

George, J. M. 2007. Creativity in organizations. Academy of Management Annals, 1: 439-477.

Gilson, L. L., \& Shalley, C. E. 2004. A little creativity goes a long way: An examination of teams' engagement in creative processes. Journal of Management, 30: 453-470.

Gong, Y., Kim, T., Zhu, J., \& Lee, D. 2013. A multilevel model of team goal orientation, information exchange, and creativity. Academy of Management Journal, 56: 827-851.

Grawitch, M. J., Munz, D. C., Elliott, E. K., \& Mathis, A. 2003. Promoting creativity in temporary problem-solving groups: The effects of positive mood and autonomy in problem definition on idea-generating performance. Group Dynamics: Theory, Research, and Practice, 7: 200-213.

Guilford, J. P. 1967. Creativity: Yesterday, today, and tomorrow. Journal of Creative Behavior, 1: $3-14$.

Hargadon, A. B., \& Bechky, B. A. 2006. When collections of creatives become creative collectives: A field study of problem solving at work. Organization Science, 17: 484-500.

Harrison, S. H., \& Rouse, E. D. 2014. Let's dance! Elastic coordination in creative group work: A qualitative study of modern dancers. Academy of Management Journal, 57: 1256-1283.

Harvey, S. 2013. A different perspective: The multiple effects of deep level diversity on group creativity. Journal of Experimental Social Psychology, 49: 822-832.

Harvey, S. 2014. Creative synthesis: Exploring the process of extraordinary group creativity. Academy of Management Review, 39: 324-343.

Hayes, A. F. 2013. Introduction to mediation, moderation, and conditional process analysis. New York: Guilford.

Herold, D. M., \& Greller, M. M. 1977. Feedback: The definition of a construct. Academy of Management Journal, 20: 142-147.

Hinsz, V. B., Tindale, R. S., \& Vollrath, D. A. 1997. The emerging conceptualization of groups 
as information processors. Psychological Bulletin, 121: 43-64.

Hoever, I. J., van Knippenberg, D., van Ginkel, W. P., \& Barkema, H. G. 2012. Fostering team creativity: Perspective taking as key to unlocking diversity's potential. Journal of Applied Psychology, 97: 982-996.

Hollenbeck, J. R., Beersma, B., \& Schouten, M. E. 2012. Beyond team types and taxonomies: A dimensional scaling conceptualization for team description. Academy of Management Review, 37: 82-106.

Homan, A. C., van Knippenberg, D., Van Kleef, G. A., \& De Dreu, C. K. W. 2007. Bridging faultlines by valuing diversity: Diversity beliefs, information elaboration, and performance in diverse work groups. Journal of Applied Psychology, 92: 1189-1199.

Hülsheger, U. R., Anderson, N., \& Salgado, J. F. 2009. Team-level predictors of innovation at work: A comprehensive meta-analysis spanning three decades of research. Journal of Applied Psychology, 94: 1128-1145.

Ilgen, D. R., \& Davis, C. 2000. Bearing bad news: Reactions to negative performance feedback. Applied Psychology: An International Review, 49: 550-565.

Ilgen, D. R., Hollenbeck, J. R., Johnson, M., \& Jundt, D. 2005. Teams in organizations: from input-process-output models to IMOI models. Annual Review of Psychology, 56: 517-543.

Kearney, E., \& Gebert, D. 2009. Managing diversity and enhancing team outcomes: The promise of transformational leadership. Journal of Applied Psychology, 94: 77-89.

Kluger, A. N., \& DeNisi, A. 1996. The effects of feedback interventions on performance: A historical review, a meta-analysis, and a preliminary feedback intervention theory. Psychological Bulletin, 119: 254-284.

Kooij-de Bode, H. J. M., van Knippenberg, D., \& van Ginkel, W. P. 2010. Good effects of bad feelings: Negative affectivity and group decision-making. British Journal of Management, 21: 375-392.

Kurtzberg, T. R. 2005. Feeling creative, being creative: An empirical study of diversity and creativity in teams. Creativity Research Journal, 17: 51-65.

Kurtzberg, T. R., \& Amabile, T. M. 2001. From Guilford to creative synergy: Opening the black box of team-level creativity. Creativity Research Journal, 13: 285-294.

Li, C.-R., Lin, C.-J., Tien, Y.-H., \& Chen, C.-M. 2015. A multilevel model of team cultural diversity and creativity: The role of climate for inclusion. Journal of Creative Behavior.

Mesch, D. J., Farh, J.-L., \& Podsakoff, P. M. 1994. Effects of feedback sign on group goal setting, strategies, and performance. Group \& Organization Management, 19: 309-333.

Miron-Spektor, E., Erez, M., \& Naveh, E. 2011. The effect of conformist and attentive-to-detail members on team innovation: Reconciling the innovation paradox. Academy of Management Journal, 54: 740-760.

Mook, D. G. 1983. In defense of external invalidity. American Psychologist, 38: 379-387.

Nadler, A. 1979. The effects of feedback on task group behavior: A review of the experimental research. Organizational Behavior and Human Decision Processes, 23: 309-338.

Nijstad, B. A., Diehl, M., \& Stroebe, W. 2003. Cognitive stimulation and interference in idea generating groups. In P. B. Paulus \& B. A. Nijstad (Eds.), Group creativity: Innovation through collaboration: 137-159. Oxford, UK: Oxford University Press.

Okhuysen, G. A., \& Eisenhardt, K. M. 2002. Integrating knowledge in groups: Interventions enable flexibility. Organization Science, 13: 370-386.

Oldham, G. R., \& Cummings, A. 1996. Employee creativity: Personal and contextual factors at work. Academy of Management Journal, 39: 607-634. 
Paulus, P. B., \& Nijstad, B. A. (Eds.). 2003. Group creativity: Innovation through collaboration. Oxford, UK: Oxford University Press.

Podsakoff, P. M., \& Farh, J.-L. 1989. Effects of feedback sign and credibility task performance. Organizational Behavior and Human Decision Processes, 44: 45-67.

Reber, R., Schwarz, N., \& Winkielman, P. 2004. Processing fluency and aesthetic pleasure: Is beauty in the perceiver's processing experience? Personality and Social Psychology Review, 8: 364-382.

Rucker, D. D., Preacher, K. J., Tormala, Z. L., \& Petty, R. E. 2011. Mediation analysis in Social Psychology: Current practices and new recommendations. Social and Personality Psychology Compass, 5: 359-371.

Shen, W., Kiger, T. B., Davies, S. E., Rasch, R. L., Simon, K. M., et al. 2011. Samples in Applied Psychology: Over a decade of research in review. Journal of Applied Psychology, 96: 1055-1064.

Shin, S. J., \& Zhou, J. 2007. When is educational specialization heterogeneity related to creativity in research and development teams? Transformational leadership as a moderator. Journal of Applied Psychology, 92: 1709-1721.

Stasser, G., \& Birchmeier, Z. 2003. Group creativity and collective choice. In P. B. Paulus \& B. A. Nijstad (Eds.), Group creativity: Innovation through collaboration: 85-109. Oxford, UK: Oxford University Press.

Staw, B. M. 1975. Attributing the "causes" of performance: An alternative interpretation of cross-sectional research on organizations. Organizational Behavior and Human Decision Processes, 13: 414-432.

Sung, S. Y., \& Choi, J. N. 2012. Effects of team knowledge management on the creativity and financial performance of organizational teams. Organizational Behavior and Human Decision Processes, 118: 4-13.

Taggar, S. 2001. Group composition, creative synergy, and group performance. Journal of Creative Behavior, 35: 261-286.

Tierney, P., \& Farmer, S. M. 2002. Creative self-efficacy: Its potential antecedents and relationship to creative performance. Academy of Management Journal, 45: 1137-1148.

Torrance, P. E. 1971. Stimulation, enjoyment, and originality in dyadic creativity. Journal of Educational Psychology1, 62: 45-48.

Tsai, W. C., Chi, N. W., Grandey, A. A., \& Fung, S. C. 2012. Positive group affective tone and team creativity: Negative group affective tone and team trust as boundary conditions. Journal of Organizational Behavior, 33: 638-656.

van de Ven, A. H. 2007. Engaged Scholarship: Creating Knowledge for Science and Practice. Oxford, UK: Oxford University Press.

van Dijk, H., van Engen, M. L., \& van Knippenberg, D. 2012. Defying conventional wisdom: A meta-analytical examination of the differences between demographic and job-related diversity relationships with performance. Organizational Behavior and Human Decision Processes, 119: 38-53.

van Ginkel, W. P., \& van Knippenberg, D. 2008. Group information elaboration and group decision making: The role of shared task representations. Organizational Behavior and Human Decision Processes, 105: 82-97.

van Ginkel, W., Tindale, R. S., \& van Knippenberg, D. 2009. Team reflexivity, development of shared task representations, and the use of distributed information in group decision making. Group Dynamics: Theory, Research, and Practice, 13: 265-280. 
van Knippenberg, D. 2017. Team innovation. Annual Review of Organizational Psychology and Organizational Behavior, 4.

van Knippenberg, D., De Dreu, C. K. W., \& Homan, A. C. 2004. Work group diversity and group performance: an integrative model and research agenda. Journal of Applied Psychology, 89: 1008-1022.

van Knippenberg, D., van Ginkel, W. P., \& Homan, A. C. 2013. Diversity mindsets and the performance of diverse teams. Organizational Behavior and Human Decision Processes, 121: 183-193.

Watson, D., Clark, L. A., \& Tellegen, A. 1988. Development and validation of brief measures of positive and negative affect: The PANAS scales. Journal of Personality and Social Psychology, 54: 1063-1070.

Watson, W. E., Kumar, K., \& Michaelsen, L. K. 1993. Cultural diversity's impact on interaction processes and performance: Comparing homogeneous and diverse task groups. Academy of Management Journal, 36: 590-602.

Weingart, L. R. 1997. How did they do that? The ways and means of studying group processes. Research in Organizational Behavior, 19: 189-239.

Weldon, E., \& Weingart, L. R. 1993. Group goals and group performance. British Journal of Social Psychology, 32: 307-334.

Williams, S. D. 2002. Self-esteem and the self-censorship of creative ideas. Personnel Review, 31: 495-503.

Winkielman, P., \& Cacioppo, J. T. 2001. Mind at ease puts a smile on the face:

Psychophysiological evidence that processing facilitation elicits positive affect. Journal of Personality and Social Psychology, 81: 989-1000.

Wittenbaum, G. M., Hubbell, A. P., \& Zuckerman, C. 1999. Mutual enhancement: Toward an understanding of the collective preference for shared information. Journal of Personality and Social Psychology, 77: 967-978.

Wofford, J. C., \& Goodwin, V. L. 1990. Effects of feedback on cognitive processing and choice of decision style. Journal of Applied Psychology, 75: 603-612.

Wuchty, S., Jones, B. F., \& Uzzi, B. 2007. The increasing dominance of teams in production of knowledge. Science, 316: 1036-1039.

Zellmer-Bruhn, M. E. 2003. Interruptive Events and Team Knowledge Acquisition. Management Science, 49: 514-528.

Zhou, J. 1998. Feedback valence, feedback style, task autonomy, and achievement orientation: Interactive effects on creative performance. Journal of Applied Psychology, 83: 261-276.

Zhou, J. 2008. Promoting creativity through feedback. In J. Zhou \& C. E. Shalley (Eds.), Handbook of Organizational Creativity: 125-145. New York: Lawrence Erlbaum.

Zhou, J., \& Shalley, C. E. 2011. Deepening our understanding of creativity in the workplace: A review of different approaches to creativity research. In S. Zedeck (Ed.), APA Handbook of Industrial and Organizational Psychology, vol. 1: 275-302. APA.

Ziller, R. C., Behringer, R. D., \& Goodchilds, J. D. 1962. Group creativity under conditions of success or failure and variations in group stability. Journal of Applied Psychology, 46: 4349. 
TABLE 1

Descriptive statistics and correlations

\begin{tabular}{|c|c|c|c|c|c|c|c|c|c|c|c|c|}
\hline & Mean & SD & 1 & 2 & 3 & 4 & 5 & 6 & 7 & 8 & 9 & 10 \\
\hline 1. Diversity & 0.47 & 0.50 & -- & - & -- & -- & -- & -- & -- & -- & -- & -- \\
\hline 2. Feedback valence & 0.51 & 0.50 & -.05 & -- & -- & -- & -- & -- & -- & -- & -- & -- \\
\hline $\begin{array}{l}\text { 3. Feedback valence } \\
\text { manipulation check }\end{array}$ & 3.18 & 0.95 & -.09 & $.94 * *$ & -- & .09 & -.16 & -.14 & $.37 * *$ & .22 & -.16 & -.19 \\
\hline $\begin{array}{l}\text { 4. Diversity manipulation } \\
\text { check }\end{array}$ & 0.30 & 0.16 & $.78 * *$ & .04 & .02 & -- & -.05 & .11 & .02 & -.06 & -.13 & .19 \\
\hline 5. Information elaboration & 3.37 & 1.14 & .22 & -.06 & -.12 & .17 & -- & $.36^{* *}$ & -.01 & -.00 & $.25^{*}$ & $.38 * *$ \\
\hline 6. Generative processing & 2.63 & 2.07 & .01 & .02 & -.03 & .10 & $.52 * *$ & -- & $.24 *$ & $.28 *$ & $.51 * *$ & $.45^{* *}$ \\
\hline 7. Team creative efficacy & 3.61 & 0.54 & .08 & $.54 * *$ & $.60 * *$ & .11 & .04 & $.23^{*}$ & -- & .65 & .06 & -.05 \\
\hline 8. Team positive affect & 3.28 & 0.47 & .11 & $.40 * *$ & $.44 * *$ & .10 & .06 & $.28^{*}$ & $.73^{* *}$ & -- & .15 & .07 \\
\hline 9. Number of ideas & 4.73 & 2.87 & -.09 & $-.23 *$ & $-.27 *$ & -.14 & $.37 * *$ & $.57 * *$ & -.05 & .05 & -- & -.04 \\
\hline 10. Team creativity & 14.98 & 7.12 & .15 & .13 & .05 & $.24 *$ & $.56 * *$ & $.57 * *$ & .11 & .19 & .10 & -- \\
\hline
\end{tabular}

Note: Diversity and feedback valence are dummy-coded variables $(0=$ homogeneous; $0=$ negative $)$. All correlations are reported at the team level. Correlations above the diagonal are partial correlations controlling for the effect of the experimental conditions and their interaction. ${ }^{*} p<.05^{* *} p<.01$ 
TABLE 2

Regression results for the moderated mediation model

\begin{tabular}{|c|c|c|c|c|c|}
\hline Predictor & $b$ & $S E$ & $\beta$ & $t$ & $\operatorname{Adj.R^{2}}$ \\
\hline Model 1: Creativity & & & & & $.24^{* * * *}$ \\
\hline Feedback valence & 8.39 & 1.95 & .59 & $4.31^{* * *}$ & \\
\hline Diversity & 9.12 & 2.02 & .64 & $4.52^{* * *}$ & \\
\hline $\begin{array}{l}\text { Feedback valence } \mathrm{x} \\
\text { diversity }\end{array}$ & -13.55 & 2.82 & -.81 & $-4.79^{* * * *}$ & \\
\hline \multicolumn{5}{|c|}{ Model 2a: Information elaboration } & $.35^{\text {*** }}$ \\
\hline Feedback valence & 1.16 & 0.29 & .51 & $3.97^{* * *}$ & \\
\hline Diversity & 1.84 & 0.30 & .80 & $6.08^{* * * *}$ & \\
\hline $\begin{array}{l}\text { Feedback valence } \mathrm{x} \\
\text { diversity }\end{array}$ & -2.63 & 0.42 & -.97 & $6.24^{* * * *}$ & \\
\hline \multicolumn{5}{|c|}{ Model 2b: Generative processing } & $.19^{* * *}$ \\
\hline Feedback valence & 1.99 & 0.59 & .48 & $3.39^{* *}$ & \\
\hline Diversity & 2.11 & 0.61 & .51 & $3.46^{* *}$ & \\
\hline $\begin{array}{l}\text { Feedback valence } \mathrm{x} \\
\text { diversity }\end{array}$ & -3.95 & 0.85 & -.81 & $-4.67^{* * * *}$ & \\
\hline \multicolumn{5}{|l|}{$\begin{array}{l}\text { diversity } \\
\text { Model 3: Creativity }\end{array}$} & $.41^{* * *}$ \\
\hline Feedback valence & 3.91 & 1.96 & .27 & 1.99 & \\
\hline Diversity & 3.34 & 2.22 & .24 & 1.50 & \\
\hline $\begin{array}{l}\text { Feedback valence } \mathrm{x} \\
\text { diversity }\end{array}$ & -4.16 & 3.18 & -.25 & -1.31 & \\
\hline $\begin{array}{l}\text { Information } \\
\text { elaboration }\end{array}$ & 1.71 & 0.74 & .28 & $2.30^{*}$ & \\
\hline Generative processing & 1.22 & 0.37 & .35 & $3.29^{* *}$ & \\
\hline
\end{tabular}

Note: Diversity and feedback valence are dummy-coded $(0=$ homogeneous; negative). For analyses involving the video-coded measures (models $2 \mathrm{a}$ through $3 \mathrm{~b}$ ) the sample size is $N=77$.

${ }^{*} p<.05$

${ }^{* * *} p<.01$

${ }^{* * *} p<.001$ 


\section{FIGURE 1}

\section{Research model}

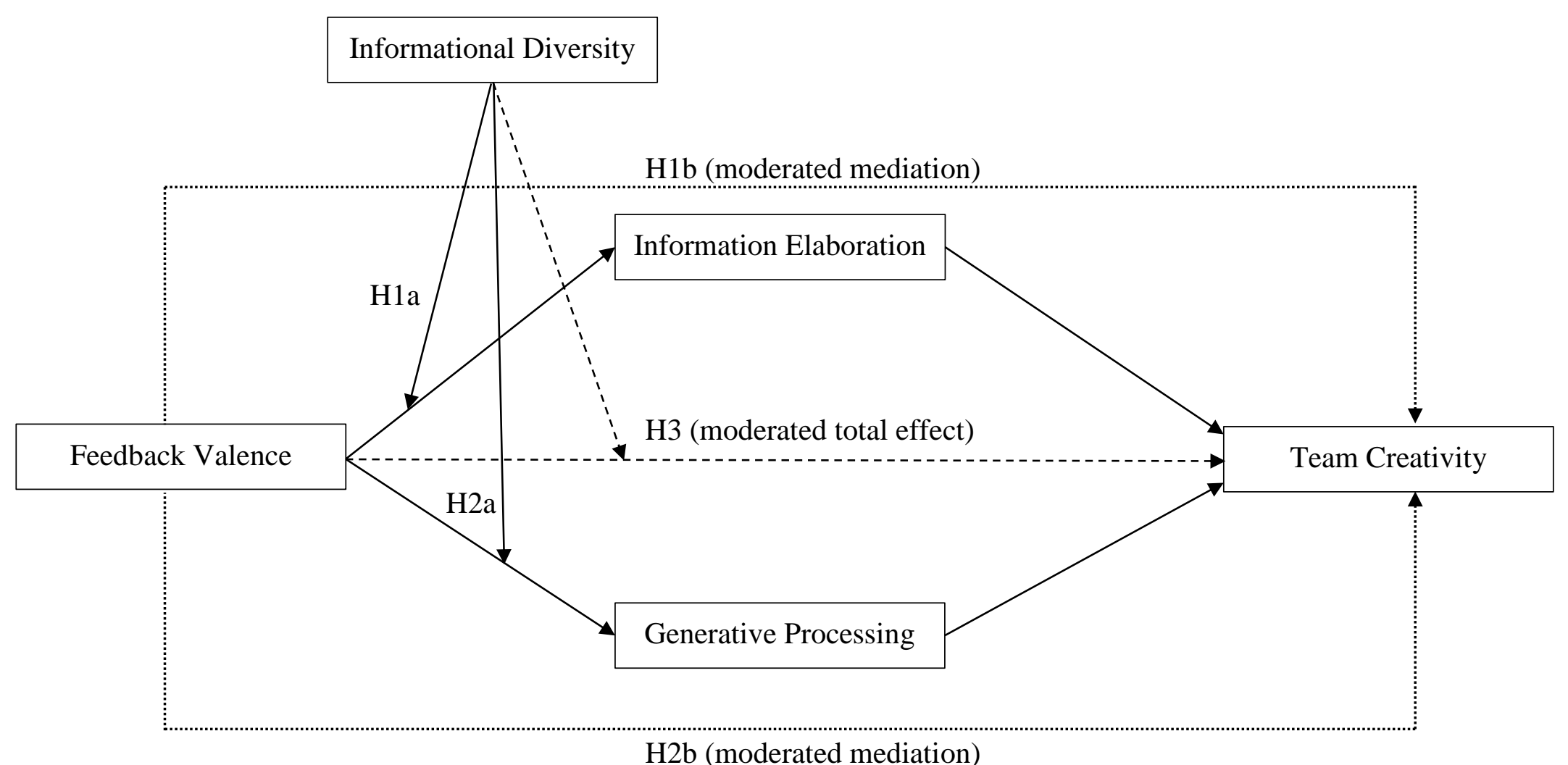

Note: Research model with the interaction between feedback valence and diversity, the mediating processes information elaboration and generative processing, and the outcome variable team creativity. Dotted lines represent indirect effects of the interaction, dashed lines represent total effects. 


\section{FIGURE 2}

Interaction between feedback valence and informational diversity on team creativity

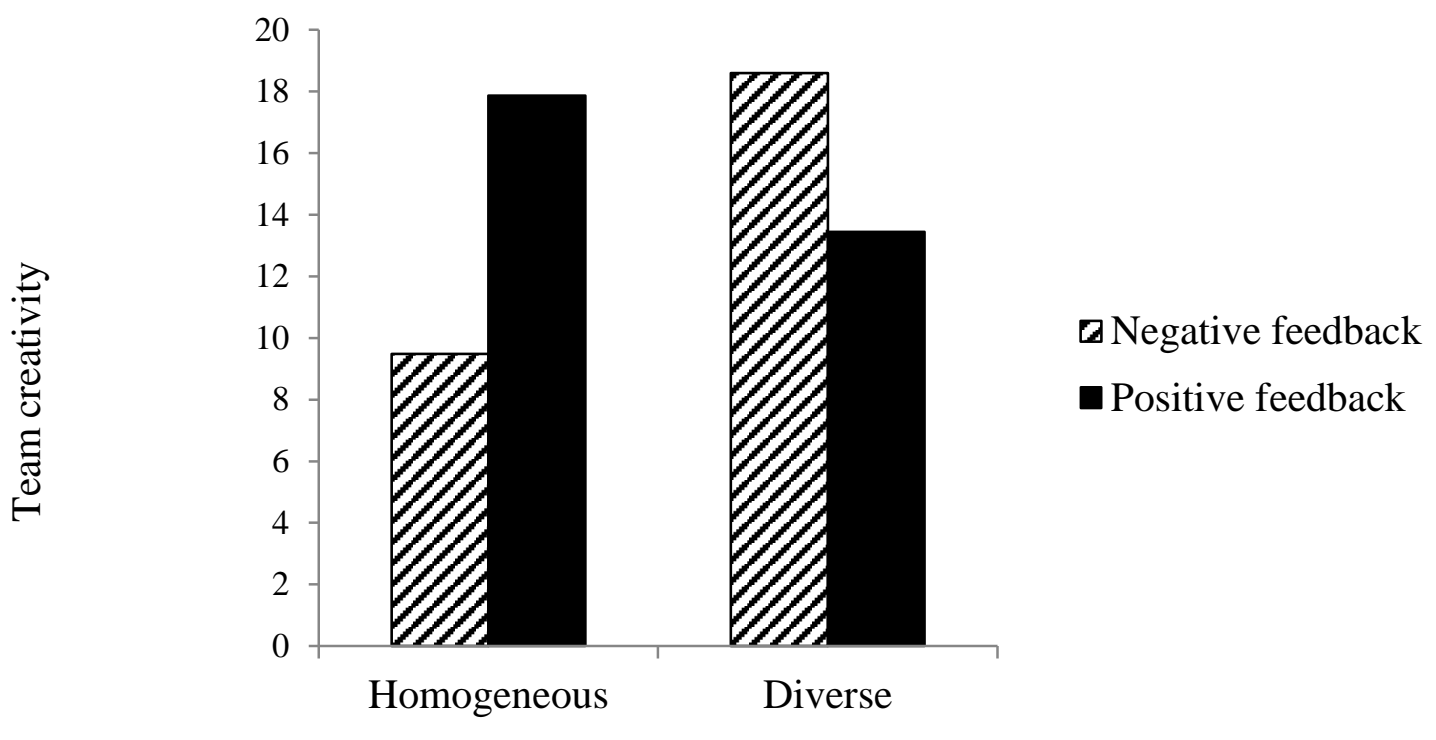




\section{FIGURE 3}

Conditional direct and indirect effects for homogeneous and diverse teams

(3A) Direct and indirect effects for informationally homogeneous teams

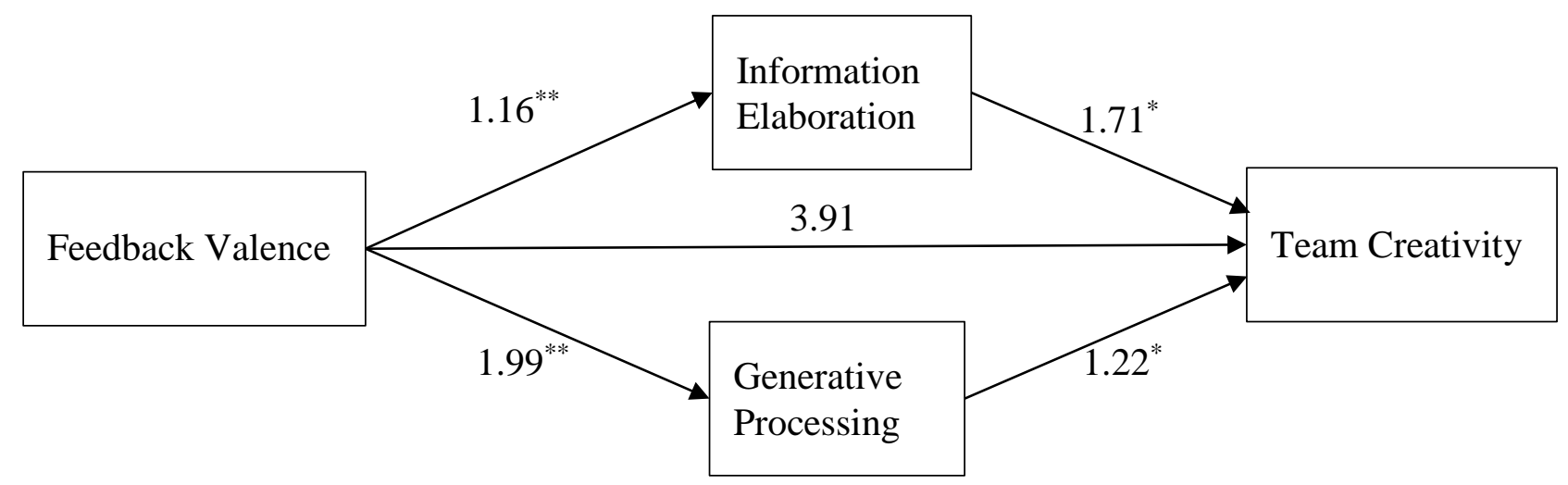

Indirect effect through elaboration: $b=1.99, S E=0.89, C I: 0.47 ; 3.97$

Indirect effect through generative processing: $b=2.43, S E=1.37, C I: 0.43 ; 5.85$

(3B) Direct and indirect effects for informationally diverse teams

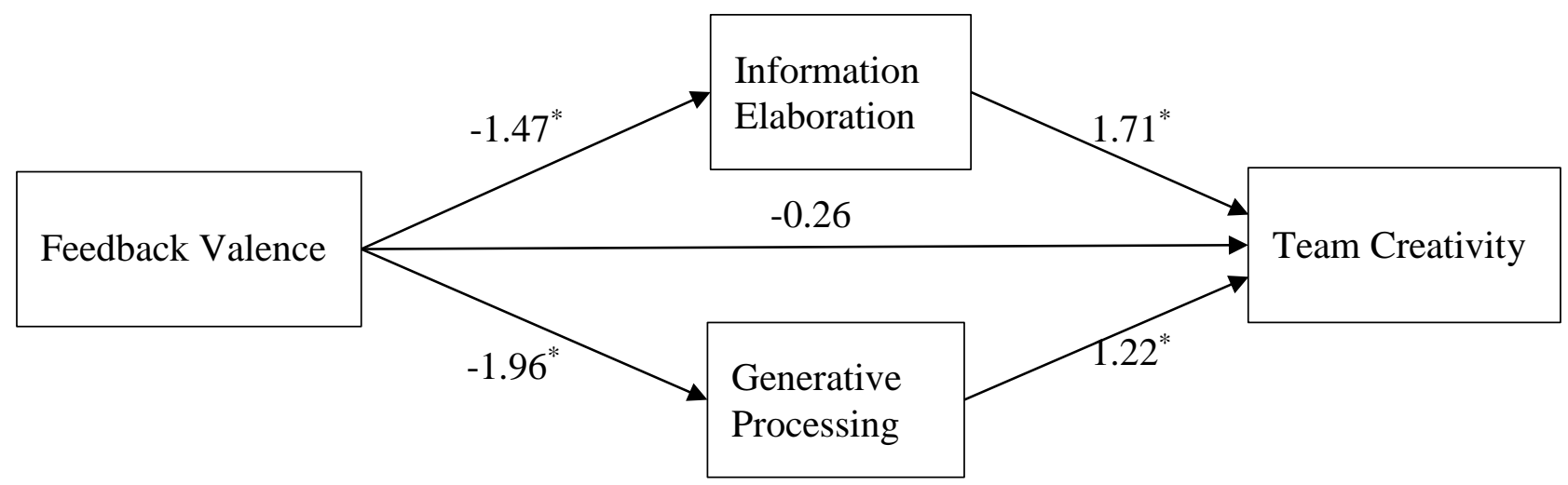

Indirect effect through elaboration: $b=-2.51, S E=1.29, C I:-5.59 ;-0.48$

Indirect effect through generative processing: $b=-2.39, S E=1.41, C I:-6.69 ;-0.48$

Note: ${ }^{*} p<.05 ;{ }^{* *} p<.01$ 


\section{BIOGRAPHICAL SKETCHES}

Inga J. Hoever (ihoever@ rsm.nl) is an Assistant Professor of Organizational Behavior at the Rotterdam School of Management, Erasmus University Rotterdam. Her research focuses on workplace creativity, team excellence, and their intersection. She received her $\mathrm{PhD}$ in Management from the Rotterdam School of Management, Erasmus University Rotterdam.

Jing Zhou (jzhou@ rice.edu) is Houston Endowment Professor of Management at the Jones Graduate School of Business at Rice University. Her research interests are creativity, innovation, and entrepreneurship. Recent projects include understanding novelty and creativity recognition, identifying unusual antecedents of creativity, and linking employee creativity to organizational innovation and firm performance.

Daan van Knippenberg is Joseph F. Rocereto Chair of Leadership at LeBow College of Business, Drexel University. His main research insterests are in leadership, diversity, teams, and creativity. Daan is Co-Editor in Chief of Academy of Management Annals, and was Founding Editor of Organizational Psychology Review, and Associate Editor of Academy of Management Journal, Organizational Behavior and Human Decision Processes, and Journal of Organizational Behavior. He is a Fellow of the Academy of Management, of the Society for Industrial and Organizational Psychology, and of the American Psychological Association. 